\title{
1 Completion of the gut microbial epi-bile acid pathway
}

3 Heidi L. Doden ${ }^{\mathrm{a}, \mathrm{b}}$, Patricia G. Wolf ${ }^{\mathrm{a}, \mathrm{b}, \mathrm{c}, \mathrm{d}, \mathrm{e}}$, H. Rex Gaskins ${ }^{\mathrm{a}, \mathrm{b}, \mathrm{c}, \mathrm{f}}$, Karthik Anantharaman ${ }^{\mathrm{g}}$, João M.

$4 \quad$ P. Alves ${ }^{\mathrm{h}}$ and Jason M. Ridlon ${ }^{\mathrm{a}, \mathrm{b}, \mathrm{c}, \mathrm{f}, \mathrm{i} *}$

$5{ }^{a}$ Carl R. Woese Institute for Genomic Biology, University of Illinois at Urbana Champaign,

6 Urbana, IL, USA; ${ }^{b}$ Department of Animal Sciences, University of Illinois at Urbana Champaign,

7 Urbana, IL, USA; ${ }^{c}$ Division of Nutritional Sciences, University of Illinois at Urbana Champaign,

8 Urbana, IL, USA; ${ }^{d}$ Institute for Health Research and Policy, University of Illinois, Chicago, IL,

9 USA; ${ }^{e}$ Cancer Education and Career Development Program, University of Illinois, Chicago, IL,

10 USA; ${ }^{f}$ Cancer Center at Illinois, Urbana, IL, USA; ${ }^{g}$ Department of Bacteriology, University of

11 Wisconsin-Madison, Madison, WI, USA; ${ }^{h}$ Department of Parasitology, Institute of Biomedical

12 Sciences, University of São Paulo, São Paulo, Brazil; ${ }^{i}$ Department of Microbiology and

13 Immunology, Virginia Commonwealth University, Richmond, VA, USA

14 *Corresponding author: Jason M. Ridlon; jmridlon@illinois.edu 


\section{Completion of the gut microbial epi-bile acid pathway}

\section{ABSTRACT}

18 Bile acids are detergent molecules that solubilize dietary lipids and lipid-soluble vitamins. Humans

19 synthesize bile acids with $\alpha$-orientation hydroxyl groups which can be biotransformed by gut microbiota to

20 toxic, hydrophobic bile acids, such as deoxycholic acid (DCA). Gut microbiota can also convert hydroxyl

21 groups from the $\alpha$-orientation through an oxo-intermediate to the $\beta$-orientation, resulting in more

22 hydrophilic, less toxic bile acids. This interconversion is catalyzed by regio- (C-3 vs. C-7) and

23 stereospecific ( $\alpha$ vs. $\beta$ ) hydroxysteroid dehydrogenases (HSDHs). So far, genes encoding the urso- $(7 \alpha-$

$24 \mathrm{HSDH} \& 7 \beta-\mathrm{HSDH})$ and iso- (3 $\alpha-\mathrm{HSDH} \& 3 \beta-\mathrm{HSDH})$ bile acid pathways have been described. Recently,

25 multiple human gut clostridia were reported to encode $12 \alpha-\mathrm{HSDH}$, which interconverts DCA and 12-

26 oxolithocholic acid (12-oxoLCA). 12ß-HSDH completes the epi-bile acid pathway by converting 12-

27 oxoLCA to the 12ß-bile acid denoted epiDCA; however, gene(s) encoding this enzyme have yet to be

28 identified. We confirmed 12ß-HSDH activity in cultures of Clostridium paraputrificum ATCC 25780.

29 From six candidate C. paraputrificum ATCC 25780 oxidoreductase genes, we discovered the first gene

30 (DR024_RS09610) encoding bile acid 12ß-HSDH. Phylogenetic analysis revealed unforeseen diversity

31 for $12 \beta-\mathrm{HSDH}$, leading to validation of two additional bile acid $12 \beta-\mathrm{HSDH}$ through a synthetic biology

32 approach. By comparison to a previous phylogenetic analysis of $12 \alpha-\mathrm{HSDH}$, we identified the first potential

33 C-12 epimerizing strains: Collinsella tanakaei YIT 12063 and Collinsella stercoris DSM 13279. A Hidden

34 Markov Model search against human gut metagenomes located putative $12 \beta-H S D H$ genes in about $30 \%$ of

35 subjects within the cohorts analyzed, indicating this gene is relevant in the human gut microbiome.

37 Keywords: bile acid, hydroxysteroid dehydrogenase, deoxycholic acid, 12-oxolithocholic acid, 38 epi-bile acid, iso-bile acid, urso-bile acid 


\section{Introduction}

The human liver produces all 14 enzymes necessary to convert cholesterol into the

42 dihydroxy bile acid chenodeoxycholic acid ( $3 \alpha, 7 \alpha$-dihydroxy-5 $\beta$-cholan-24-oic acid; CDCA) and

43 the trihydroxy bile acid cholic acid $\left(3 \alpha, 7 \alpha, 12 \alpha\right.$-trihydroxy-5 $\beta$-cholan-24-oic acid; CA). ${ }^{1}$ These bile

44 acids are conjugated to taurine or glycine in the liver helping to lower the $p K_{a}$ and maintain

45 solubility, impermeability to cell membranes, and lower the critical micellar concentration,

46 allowing for efficient emulsification of dietary lipids and lipid-soluble vitamins. ${ }^{2}$ Bile acids are

47 effective detergents owing to the $\alpha$-orientation of the hydroxyl groups which produce a

48 hydrophilic-face above the plane of the cyclopentanephenanthrene steroid nucleus, and a

49 hydrophobic-face below the plane of the hydrocarbon rings. ${ }^{1}$ Conjugated bile acids emulsify lipids

50 throughout the duodenum, jejunum, and ileum. Once bile acids reach the terminal ileum, high

51 affinity transporters (intestinal bile acid transporter, IBAT) actively transport both conjugated and

52 unconjugated bile acids from the intestinal lumen into ileocytes where they are bound to ileal bile

53 acid binding protein (IBABP) and exported across the basolateral membrane into portal circulation

54 and returned to the liver. ${ }^{3}$ This process of recycling of bile acids is known as the enterohepatic

55 circulation (EHC), responsible for recirculating the $\sim 2 \mathrm{~g}$ bile acid pool 8-10 times daily. While

$56 \sim 95 \%$ efficient, roughly $600-800 \mathrm{mg}$ bile acids escape active transport and enter the large

57 intestine. $^{2}$

Anaerobic bacteria adapted to inhabiting the large intestine have evolved enzymes to

59 modify the structure of host bile acids. ${ }^{2}$ Conjugated bile acids are hydrolyzed, releasing the amino

60 acids, by bile salt hydrolases $(\mathrm{BSH})$ in diverse gut bacteria representing the major phyla, including

61 Bacteroidetes, Firmicutes, and Actinobacteria as well as the domain Archaea. ${ }^{4}$ By contrast, the

62 unconjugated primary bile acids CA and CDCA are $7 \alpha$-dehydroxylated by a select few species of 
63 gram-positive Firmicutes mostly in the genus Clostridium, forming deoxycholic acid $(3 \alpha, 12 \alpha-$

64 dihydroxy-5 $\beta$-cholan-24-oic acid; DCA) and lithocholic acid (3 $\alpha$-hydroxy-5 $\beta$-cholan-24-oic acid;

65 LCA), respectively. ${ }^{1,5}$ The secondary bile acids DCA and LCA have increased hydrophobicity

66 relative to their primary counterparts, which is associated with elevated toxicity. ${ }^{6}$ DCA and LCA

67 have been causally linked to cancers of the colon ${ }^{7}, \operatorname{liver}^{8}$, and esophagus ${ }^{9}$. Importantly, gut

68 microbiota can produce less toxic oxo-bile acids and $\beta$-hydroxy bile acids as well. ${ }^{6}$

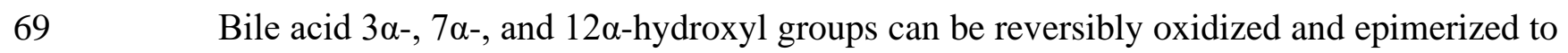

70 the $\beta$-orientation by pyridine nucleotide-dependent hydroxysteroid dehydrogenases (HSDHs)

71 distributed across the major phyla including Firmicutes, Bacteroidetes, Actinobacteria,

72 Proteobacteria, as well as methanogenic archaea. ${ }^{1,10} \mathrm{HSDH}$ enzymes that recognize bile acids are

73 regio- (C-3 vs. C-7) and stereospecific ( $\alpha$ vs. $\beta$ ) for hydroxyl groups decorating the steroid nucleus.

74 Thus, bile acid $12 \alpha-\mathrm{HSDH}$ reversibly converts the C-12 position of bile acids from the $\alpha$ -

75 orientation, such as on DCA, to 12-oxo bile acids, such as 12 -oxolithocholic acid (12-oxoLCA). ${ }^{11-}$

$76{ }^{14}$ Bile acid 12 $\beta$-HSDH completes the epimerization by interconverting 12-oxo bile acids to the

$7712 \beta$-configuration, forming epi-bile acids. We recently identified and characterized NAD(H)- and

$78 \mathrm{NADP}(\mathrm{H})$-dependent 12 $\alpha-\mathrm{HSDHs}$ from Eggerthella sp. CAG:298 ${ }^{15}$, Clostridium scindens, C.

79 hylemonae, and Peptacetobacter hiranonis (formerly Clostridium hiranonis) ${ }^{10}$. In addition to these

80 recently reported $12 a-H S D H s$, multiple genes encoding enzymes in the urso- (7 $\alpha-\& 7 \beta-H S D H)$

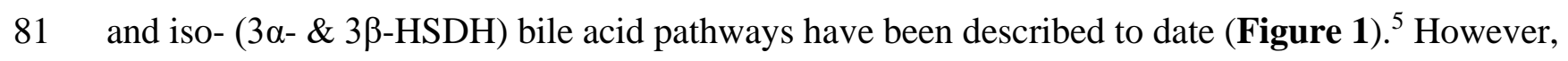

82 a gene encoding $12 \beta-\mathrm{HSDH}$ to complete the epi-bile acid pathway has not yet been reported.

83 The first indication that gut bacteria may encode $12 \beta-\mathrm{HSDH}$ was suggested by the

84 detection of 12 $\beta$-hydroxy bile acids in human feces. ${ }^{16-18}$ Edenharder and Schneider (1985) reported

$8512 \beta$-dehydrogenation of bile acids by Clostridium paraputrificum, and epimerization of DCA by 
86 co-culture with E. lenta and C. paraputrificum. ${ }^{19}$ Thereafter, Edenharder and Pfützner (1988)

87 characterized crude NADP(H)-dependent $12 \beta-\mathrm{HSDH}$ activity from $C$. paraputrificum D 762-06. ${ }^{20}$

88 However, little is known about the potential diversity of gut bacteria capable of forming $12 \beta-$

89 hydroxy bile acids that molecular analysis is predicted to yield. Here, we report the identification

90 of a gene encoding NADP(H)-dependent 12ß-HSDH from C. paraputrificum ATCC 25780 and

91 characterization of the recombinant gene products purified after heterologous expression in E. coli

92 from $C$. paraputrificum. We also identify novel taxa encoding bile acid $12 \beta-H S D H$ by

93 phylogenetic analysis, confirmed by a synthetic biology approach.

\section{Results}

\section{C. paraputrificum ATCC 25780 possesses bile acid 12B-HSDH activity}

We first investigated the bile acid metabolizing capability of $C$. paraputrificum ATCC

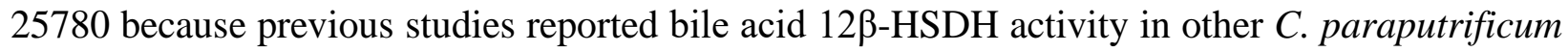
strains, but did not identify the gene(s) responsible. ${ }^{20}$ The epi-bile acid pathway of DCA involves the reversible conversion of DCA $(3 \alpha, 12 \alpha)$ to 12-oxoLCA $(3 \alpha, 12$-oxo) through the action of $12 \alpha$ -

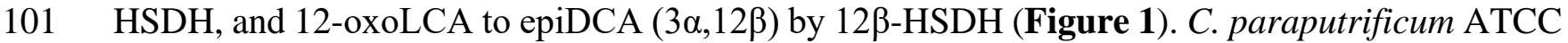

10225780 was incubated with two potential substrates of $12 \beta-H S D H, 12-o x o L C A$ and epiDCA, along

103 with DCA as a control. In order to contrast the product formed by bile acid 12 $\beta$-HSDH with that

104 formed by bile acid 12 $\alpha$-HSDH activity, Clostridium scindens ATCC 35704, which is known to 105 express $12 \alpha-\mathrm{HSDH}$, was incubated with the same substrates. When 12-oxoLCA was incubated in 106 cultures of $C$. paraputrificum ATCC 25780, the primary product eluted at 13.97 min with 391.28

$107 \mathrm{~m} / \mathrm{z}$ in negative ion mode (Figure 2). This is consistent with the elution time of epiDCA standard 108 and its 392.57 amu formula weight. With epiDCA as substrate, the culture produced a major peak 

not converted in large quantities to 12-oxoLCA (390.56 amu). C. paraputrificum incubation with

111 DCA did not result in detectable formation of 12-oxoLCA or epiDCA products. Taken together,

112 these data demonstrate $C$. paraputrificum ATCC 25780 expresses bile acid 12 $\beta$-HSDH activity,

113 but not bile acid 12 $\alpha$-HSDH. C. scindens ATCC 35704 incubation with 12-oxoLCA resulted in a

114 main product (15.57 min and $391.28 \mathrm{~m} / \mathrm{z}$ ) consistent with DCA (392.57 amu), demonstrating bile

115 acid $12 \alpha-H S D H$ activity. In addition, reaction with DCA resulted in a peak at 15.57 min and 391.28

$116 \mathrm{~m} / \mathrm{z}$ along with a peak agreeing with 12-oxoLCA at $14.34 \mathrm{~min}$ and $389.27 \mathrm{~m} / \mathrm{z}$. When epiDCA

117 was incubated with cultures of $C$. scindens ATCC 35704, we did not observe formation of 12118 oxoLCA.

\section{Identification of a gene encoding bile acid 12ß-HSDH}

After bile acid 12 $\beta$-HSDH activity was confirmed in $C$. paraputrificum ATCC 25780, its

124 chain dehydrogenase/reductase) family. ${ }^{21}$ Five SDR family oxidoreductase proteins and one

125 aldo/keto reductase were identified as $12 \beta-\mathrm{HSDH}$ candidates in the $C$. paraputrificum ATCC 12625780 genome and pursued for further study. These six genes were amplified from genomic DNA 127 of $C$. paraputrificum ATCC 25780, cloned into the pET-28a(+) vector, and overexpressed in $E$. 128 coli (Table S1). The N-terminal His 6 -tagged recombinant proteins were purified by metal-affinity 129 chromatography and resolved by SDS-PAGE (Figure 3A). 
132 SDS-PAGE. These proteins were not explored further. The other four $12 \beta$-HSDH candidates

133 (WP_027099077.1, WP_027098355.1, WP_027097937.1, WP_027098604.1) were soluble and

134 visualized by SDS-PAGE. The four soluble recombinant proteins were then screened for pyridine

135 nucleotide-dependent bile acid 12 $\beta$-HSDH activity by TLC and spectrophotometric assay.

136 Screening reactions were prepared with 12-oxoLCA and NADPH, or epiDCA and NADP ${ }^{+}$in $\mathrm{pH}^{-}$

$137 \quad 7.0$ phosphate buffer.

Only WP_027099077.1 exhibited 12ß-HSDH activity by TLC and spectrophotometric assay, which was also confirmed by LC-MS (Figure 3B). Reaction products of WP_027099077.1

140 with 12-oxoLCA and NADPH, epiDCA and $\mathrm{NADP}^{+}, \mathrm{DCA}$ and $\mathrm{NADP}^{+}$, and no substrate control

141 were subjected to LC-MS. In the presence of purified recombinant WP_027099077.1 and NADPH,

142 12-oxoLCA was reduced quantitatively ( 2 hydrogen addition) to a product that eluted at 13.12 min

143 with $391.28 \mathrm{~m} / \mathrm{z}$ in negative ion mode. This is consistent with the $392.57 \mathrm{amu}$ formula weight and

144 elution time for epiDCA based on the substrate standard. Additionally, epiDCA was oxidized to a

145 product with an elution time of $13.40 \mathrm{~min}$ at $389.27 \mathrm{~m} / \mathrm{z}$, agreeing with the retention time and

146 formula weight of 390.56 amu for authentic 12-oxoLCA. DCA (392.57 amu) was not converted

147 by WP_027099077.1 as the sole peak observed matched DCA standard at 14.60 min and 391.29

$148 \mathrm{~m} / \mathrm{z}$. The interconversion of 12-oxoLCA and epiDCA, but no activity with DCA, indicates

149 stereospecificity for the 12ß-hydroxy position. Thus, DR024_RS09610 has been identified as the

150 first gene reported that encodes bile acid 12ß-HSDH (WP_027099077.1).

151 Recombinant C. paraputrificum WP_027099077.1, hereafter referred to as Cp12 $\beta$-HSDH,

152 had a theoretical subunit molecular mass of $27.4 \mathrm{kDa}$. The observed subunit molecular mass was

$15326.4 \pm 0.5 \mathrm{kDa}$ by SDS-PAGE, calculated from three independent protein gels. WP_027099077.1

154 is predicted to be a cytosolic protein that is not membrane-associated by TMHMM v. $2.0 .^{22}$ 


\section{Biochemical characterization of recombinant Cp12ß-HSDH}

156

The approximate native molecular mass of $\mathrm{Cp} 12 \beta-\mathrm{HSDH}$ was determined by sizeexclusion chromatography. Cp12 $\beta-H S D H$ exhibited an elution volume of $15.04 \pm 0.02 \mathrm{~mL}$, corresponding to a $54.67 \pm 0.79 \mathrm{kDa}$ molecular mass relative to protein standards (Figure 4A). The size-exclusion data along with the theoretical subunit molecular mass of $27.4 \mathrm{kDa}$ suggests Cp12 $\beta$-HSDH assembles a homodimeric quaternary structure in solution. In order to optimize the enzymatic activity of $\mathrm{Cp} 12 \beta-\mathrm{HSDH}$, the conversion of pyridine nucleotides at $340 \mathrm{~nm}$ was measured in buffers between $\mathrm{pH} 6.0$ and 8.0 by spectrophotometric assay (Figure $4 \mathbf{B}$ ). The optimum $\mathrm{pH}$ for $\mathrm{Cp} 12 \beta-\mathrm{HSDH}$ in the oxidative direction with epiDCA as the substrate and $\mathrm{NADP}^{+}$ as co-substrate was $\mathrm{pH}$ 7.5. In the reductive direction where 12-oxoLCA was the substrate and NADPH the co-substrate, the optimum $\mathrm{pH}$ was 7.0.

Michaelis-Menten kinetics were performed at the $\mathrm{pH}$ optimum for each direction. In the reductive direction, Cp12 $\beta$-HSDH displayed a $K_{m}$ value for 12 -oxoLCA at $18.76 \pm 0.40 \mu \mathrm{M}$ which was similar to that of NADPH (Table 1; Figure S1). The $K_{m}$ value in the oxidative direction with epiDCA as substrate was about twice the $K_{m}$ determined for 12-oxoLCA. The $K_{m}$ for NADP ${ }^{+}$was $36.84 \pm 0.55 \mu \mathrm{M}$. The $V_{\max }$ and $k_{c a t}$ were greater in the oxidative than the reductive direction. However, the catalytic efficiency $\left(k_{c a t} / K_{m}\right)$ of 12 -oxoLCA as substrate was greater than the oxidative direction with epiDCA as substrate.

Pyridine nucleotide cofactor and bile acid substrate-specificity of Cp12 $\beta-H S D H$ were determined by relative activity compared to either 12-oxoLCA or epiDCA through spectrophotometric assay (Table 2). NAD ${ }^{+}$and NADH were not co-substrates for Cp12 $\beta-\mathrm{HSDH}$. DCA $(3 \alpha, 12 \alpha)$ as well as CA $(3 \alpha, 7 \alpha, 12 \alpha)$ were not substrates, which is expected because they are 12 $\alpha$-hydroxy bile acids not $12 \beta$-hydroxy bile acids. CDCA (chenodeoxycholic acid; $3 \alpha, 7 \alpha$ ) lacks 
178 a 12-hydroxyl group, and as expected was not a substrate. The CA derivatives 12-oxoCDCA

$179(3 \alpha, 7 \alpha, 12$-оxo) and epiCA $(3 \alpha, 7 \alpha, 12 \beta)$ had $\sim 12 \%$ and $27 \%$ activity, respectively, relative to bile

180 acids lacking a $7 \alpha$-hydroxyl group. The activity of 3,12-dioxoLCA was $\sim 19 \%$ compared to 12 -

181 oxoLCA. Altogether, the results suggest $\mathrm{Cp} 12 \beta-\mathrm{HSDH}$ is specific for NADP(H) and favors 12-

182 oxoLCA and epiDCA over their $7 \alpha$-hydroxy counterparts.

183

\section{Phylogenetic analysis of Cp12ß-HSDH}

The Cp12 $\beta$-HSDH sequence from C. paraputrificum ATCC 25780 (WP_027099077.1)

was used in a BLASTP search against the NCBI non-redundant protein database in order to

187 determine its prevalence across bacteria. A maximum likelihood phylogeny of 5,000 sequences

188 was constructed, revealing that many sequences most similar to Cp12 $\beta$-HSDH are found in

189 Firmicutes and Actinobacteria (Figure S2). Within the 5,000-member phylogeny, a subtree

190 (highlighted grey) of the most closely related proteins to Cp12 $\beta-\mathrm{HSDH}$ was selected for closer

191 inspection (Figure 5). Cp12ß-HSDH clustered most closely with other C. paraputrificum

192 sequences (WP_099327725, WP_049179624, WP_111937163). These sequences are encoded by

193 C. paraputrificum strains isolated from preterm infants, namely strain LH025, LH141, and

194 LH058 ${ }^{23}$, or isolated from feces (Gcol.A11). ${ }^{24}$

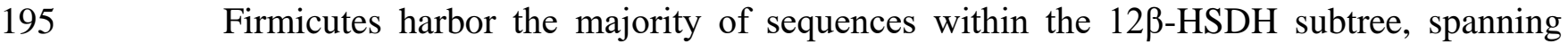
196 genera including Eisenbergiella, Ruminococcus, and Coprococcus. To determine if other 197 organisms within the tree have bile acid 12 $\beta-H S D H$ activity, the gene encoding WP_118677302.1

198 from Eisenbergiella sp. OF01-20 was synthesized by IDT in the codon-usage of E. coli (Table

199 S1), cloned into pET-28a(+), overexpressed in E. coli, and purified by affinity chromatography

200 (Figure 5). Recombinant WP_118677302.1 was screened by spectrophotometric assay with 
$\mathrm{NAD}(\mathrm{P})(\mathrm{H})$ against 12-oxoLCA, epiDCA, and DCA. Relative to Cp12 $\beta-\mathrm{HSDH}$, WP_118677302.1 exhibited 88\% activity with 12-oxoLCA, and 83\% activity with epiDCA. WP_118677302.1 did not show conversion of DCA, confirming that this enzyme has bile acid 12ß-HSDH activity (Table 2).

The subtree also contains many sequences from Actinobacteria, the genera Collinsella and and various HSDHs recognizing sterols ${ }^{25}$, including bile acid $12 \alpha-\mathrm{HSDH} .{ }^{26}$ To determine if a member of the Actinobacteria encodes a bile acid $12 \beta-\mathrm{HSDH}$, a sequence more distantly related to Cp12ß-HSDH, Olsenella sp. GAM18 WP_120179297.1, was chosen for gene synthesis and protein overexpression because it had not been shown previously to metabolize bile acids (Figure 5). 12-oxoLCA, epiDCA and DCA were tested as substrates and conversion was measured by

212 spectrophotometric assay. Recombinant WP_120179297.1 displayed activity with 12-oxoLCA at $213128 \%$ relative to $\mathrm{Cp} 12 \beta-\mathrm{HSDH}, 69 \%$ relative activity with epiDCA, and showed no reaction with

214 DCA (Table 2). These data confirm that the more distantly related WP_120179297.1 has bile acid 215 12ß-HSDH activity. Within the extended subtree are various Novosphingobium species. These

217 Alphaproteobacteria deserve mention due to their ability to biodegrade aromatic compounds, such 218 as phenanthrene ${ }^{27}$ and estrogen. ${ }^{28}$ To test if this cluster has bile acid 12ß-HSDH activity, 219 WP_007678535.1 from Novosphingobium sp. AP12 was synthesized, cloned, overexpressed, and 220 purified (Figure 5). The potential 12 $\beta-\mathrm{HSDH}$ activity of WP_007678535.1 was screened using 221 12-oxoLCA, epiDCA, and DCA as substrates. WP_007678535.1 exhibited no activity with these 222 bile acid substrates (Table 2). Because Novosphingobium strains are frequently plant-associated 223 or isolated from aquatic environments ${ }^{29}$, this enzyme may be specific for other substrates. 
The genomic context of $12 \beta-\mathrm{HSDH}$ genes from C. paraputrificum ATCC 25780,

225 Eisenbergiella sp. OF01-20, and Olsenella sp. GAM18 was explored (Figure S3). The three 12ß-

226 HSDH genes did not appear to be organized within an operon nor was the genomic context

227 conserved across these organisms.

Two organisms present in the 12ß-HSDH subtree, Collinsella tanakaei and Collinsella

stercoris (Figure 5, asterisks), were also found in a previous phylogenetic analysis of putative

12 $\alpha$-HSDHs (Doden AEM 2018). Due to strain variation within species, we inspected the

231 sequences further and determined that the pairs of HSDHs are encoded by the same strain within

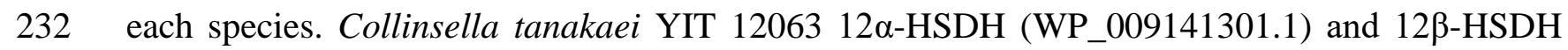

233 (WP_009140706.1) are encoded by the genes HMPREF9452_RS06335 and

234 HMPREF9452_RS03390, respectively. Collinsella stercoris DSM 13279 also contains both

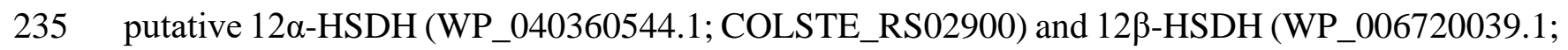

236 COLSTE_RS01465). ${ }^{10}$ While the paired activity of $12 \alpha / 12 \beta-H S D H$ has not been tested in culture,

237 these organisms may be novel epi-epimerizing strains that convert bile acid $12 \alpha$-hydroxyl groups

238 to the epi-configuration. To our knowledge, these are the first strains identified with C-12

239 epimerizing ability.

241 Hidden Markov Model search of putative 12ß-HSDH genes in human gut metagenomes

242 To understand the distribution of potential 12 $\beta-\mathrm{HSDH}$ genes in the human colonic

243 microbiome, a Hidden Markov Model (HMM) search was performed against metagenome

244 assembled genomes (MAGs) from four publicly available cohorts ${ }^{30-33}$ using reference sequences

245 from the 12 $\beta$-HSDHs characterized in this paper (Figure 5). Putative 12 $\beta$-HSDH genes inferred

246 by HMM search were found in $30 \%$ of the subjects (198/666) (Figure 6A). Twenty-two subjects 
247 exhibited two different organisms containing the gene. This gene was found in healthy subjects as

248 well as subjects with the following disease states: colorectal cancer, colorectal adenoma, fatty

249 liver, hypertension, and type 2 diabetes.

250 Two hundred twenty microbial genomes contained putative $12 \beta$-HSDH genes among

25116,936 total available genomes. Putative $12 \beta-H S D H$ genes were most often identified in the

252 phylum Firmicutes, which was dominated by genes in Lachnospira eligens (formerly Eubacterium

253 eligens) (Figure 6B). The gene from L. eligens was widespread across subjects in each of the four

254 cohorts. This large proportion of hits from L. eligens may reflect its higher relative abundance

255 allowing it to be assembled better into genomes. Sequences from this organism also appeared

256 multiple times in the 12ß-HSDH subtree (Figure 5). Lachnospira eligens is a pectin degrader

257 capable of promoting anti-inflammatory cytokine IL-10 production in vitro ${ }^{34}$ and has been

258 proposed as a probiotic for atherosclerosis ${ }^{35}$. The gene was also present in C. paraputrificum along

259 with other unidentified Clostridium sp. and Eubacterium sp. Actinobacteria had few members with

260 the gene, represented by Collinsella intestinalis, Collinsella tanakaei, and Olsenella sp.

261 Phocaeicola coprocola (formerly Bacteroides coprocola) was the only member of phylum

262 Bacteroidetes with the gene.

264 Phylogenetic analysis of regio- and stereospecific $\mathrm{HSDHs}$

265 Next, the phylogenetic relationship between Cp123-HSDH (WP_027099077.1) and other

266 regio- and stereospecific HSDHs was explored. To accomplish this, we updated the HSDH

267 phylogeny presented by Mythen et al. (2018) by including additional bacterial or archaeal HSDH

268 sequences of known or putative function along with representative eukaryotic sequences (Figure

269 7; Table S2). ${ }^{15}$ The sequences included span the known HSDH functional capacities, with some 
270 recognizing bile acids and others recognizing steroids like cortisol or progesterone. Most members

271 of each HSDH class are clustered together, which is apparent by each highlight color

272 encompassing more than one HSDH of the same known function. Furthermore, most bacterial

273 HSDHs grouped separately from their eukaryotic counterparts.

$274 \quad$ Prokaryotic sequences were interspersed among the eukaryotic with some exceptions in

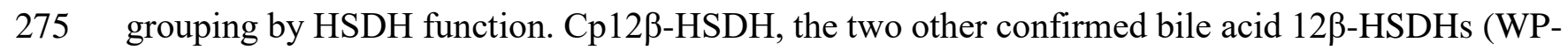

276 118677302.1, WP_120179297.1), and additional similar sequences from across our bile acid 12ß-

277 HSDH subtree formed their own cluster. These sequences shared a branch with bacterial bile acid

$27812 \alpha-\mathrm{HSDHs}$ as well as eukaryotic $3 \beta-\mathrm{HSD} / \Delta^{5} \rightarrow \Delta^{4} /$ isomerases. Bile acid $12 \alpha-\mathrm{HSDH}$ sequences

279 included various clostridia (EDS06338.1, EEG75500.1, EEA85268.1, ERJ00208.1) ${ }^{10,36}$ and

280 Eggerthella (CDD59475.1). ${ }^{15}$ Collinsella aerofaciens (EBA39192.1), which has been reported to

281 express bile acid $12 \alpha-\mathrm{HSDH}$ activity ${ }^{26}$, grouped with the known bile acid $12 \alpha-\mathrm{HSDHs}$ along with

282 two human gut archaeal sequences from Methanosphaera stadtmanae and Methanobrevibacter

283 smithii.

284 Clostridial (gram-positive) bile acid 7 $\alpha$-HSDHs (AAB61151.1 etc.) ${ }^{37}$ clustered separately

285 from those expressed by E. coli (BAA01384.1) ${ }^{38}$ and those predicted in Bacteroides (gram-

286 negative), similarly to the Mythen et. al. (2018) phylogeny. Bile acid 7 $\beta$-HSDHs did not closely

287 cluster with other classes of bacterial HSDHs. Instead, the nearest neighbours to the three known

288 bile acid 7ß-HSDHs (WP_006236005.1, WP_004843516.1, AET80684.1) $)^{25,39,40}$ included in this

289 tree were eukaryotic steroid $11 \beta$ - and $17 \beta$-HSDs.

290 Bacterial 3 $\alpha$-HSDHs clustered together, excluding one outlier from Eggerthella lenta

291 (ACV54671.1). ${ }^{41}$ Within the bile acid 3 $\alpha$-HSDH group, four enzymes predicted with this function

292 formed a separate branch apart from the confirmed bile acid $3 \alpha$-HSDHs. Likewise, three known 
293 bile acid 3ß-HSDHs grouped together (ACV55294.1, ACV54192.1, EDN78833.1) ${ }^{41}$, while one

294 Eggerthella sequence was most closely related to putative bile acid 3 $\beta$-HSDHs from Lactobacillus

295 spp. identified by BLAST search in Mythen et. al (2018).

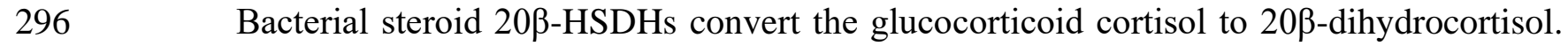

297 Two experimentally confirmed 20ß-HSDHs (WP_003810233.1, WP_051643274.1) ${ }^{42,43}$ grouped

298 with putative sequences from both gut and urinary tract isolates. To date, only one steroid $20 \alpha-$

299 HSDH sequence, which interconverts cortisol and 20 $\alpha$-dihydrocortisol, has been reported (C.

300 scindens EDS07887.1). ${ }^{44,45}$ Therefore, we performed a BLASTP search and found two sequences

301 with high similarity, WP_145772308.1 from Denitratisoma oestradiolicum DSM 16959 and

302 WP_107631222.1 from Intestinibacillus sp. Marseille-P4005. D. oestradiolicum DSM 16959 was

303 isolated from sludge in a municipal wastewater treatment plant and can use $17 \beta$-estradiol as a sole

304 carbon and energy source. ${ }^{46}$ Intestinibacillus massiliensis strain Marseille-P3216, a close relative

305 to Intestinibacillus sp. Marseille-P4005 found in our tree, was isolated from the human colon and

306 is most closely related to the species Butyricicoccus desmolans (formerly Eubacterium desmolans)

307 by $16 \mathrm{~S}$ rRNA gene sequence. ${ }^{47}$ Interestingly, B. desmolans ATCC 43058 encodes a 20ß-HSDH

308 (WP_051643274.1). ${ }^{43}$

309 Eukaryotic HSDH sequences, typically denoted HSD, were spread throughout the

310 phylogeny, but generally grouped with like sequences. The $17 \beta$ - and $11 \beta$-HSD sequences did not

311 form a group, instead clustering by type. For example, Homo sapiens 11ß-HSD type 1

312 (NP_861420.1) was closely related to Rattus norvegicus 11 $\beta$-HSD type 1 (NP_058776.2) and

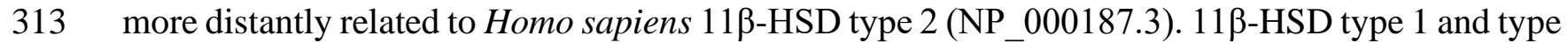

3142 both interconvert steroids between active and inactive forms, such as cortisol and cortisone. ${ }^{48}$ 
315 However, 11 $\beta$-HSD type 1 primarily acts as a reductase in many tissues while $11 \beta$-HSD type 2

316 functions as a dehydrogenase. ${ }^{48}$

\section{Discussion}

Microbial bile acid HSDHs have been studied since the early 1970s, with much of the

320 original work focusing on $3 \alpha-$ and $7 \alpha$-HSDHs. ${ }^{14,49}$ Thereafter, $3 \beta-, 7 \beta-$ and $12 \alpha-H S D H$ activity

321 was observed in cultures of various microbiota ${ }^{1}$, including Eggerthella lenta (formerly

322 Eubacterium lentum) which is capable of oxidizing CA and DCA at C-12 and epimerizing bile

323 acids at C-3. ${ }^{50}$ In the mid-1980s, C. paraputrificum, C. tertium, and Clostridioides difficile each in

324 binary cultures with $E$. lenta were shown to epimerize DCA via a 12-oxo-intermediate to

325 epiDCA. ${ }^{19}$ Since then, HSDH genes encoding the iso- and urso-bile acid pathways and $12 \alpha-\mathrm{HSDH}$

326 were identified, but not $12 \beta-\mathrm{HSDH} .{ }^{5}$ In this work, we identified the first bile acid $12 \beta-\mathrm{HSDH}$ gene,

327 completing the microbial epi-bile acid pathway.

Edenharder \& Pfützner (1988) initially characterized NADP(H)-dependent 12ß-HSDH

329 from crude extracts of the fecal isolate C. paraputrificum strain D 762-06, with differing results

330 from our findings. ${ }^{20} \mathrm{Gel}$ filtration analysis of crude extract from C. paraputrificum strain D 762-

33106 suggested a molecular mass of $126 \mathrm{kDa}$; whereas our current work with Cp12ß-HSDH from

332 ATCC 25780 is estimated at $54.6 \mathrm{KDa}$ by gel filtration chromatography. The strain used in this

333 study, C. paraputrificum ATCC 25780, was also isolated from feces. ${ }^{51}$ It is possible that these are

334 the same NADP(H)-dependent enzymes by sequence from two different strains of $C$.

335 paraputrificum and that the recombinant protein quaternary structure is unstable, resulting in a

336 dimeric form in our study. Alternatively, these bacterial strains may have distinct versions of $12 \beta-$

337 HSDH with different amino acid sequences, as we have shown previously for $12 \alpha-\mathrm{HSDH}$ from 
Eggerthella lenta. ${ }^{15,52}$ Indeed, the $12 \beta-\mathrm{HSDH}$ from C. paraputrificum strain D 762-06 was reported to be partially membrane associated, whereas hydropathy prediction by TMHMM v. 2.0 found no evidence of transmembrane domains in Cp12 $\beta-H S D H$. In addition, $\mathrm{pH}$ optima for the

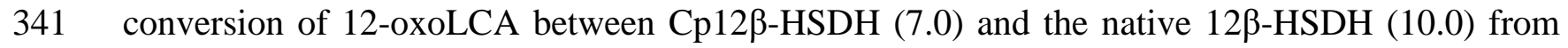

342 strain D 762-06 differed. Oxidation of epiDCA was optimal at $\mathrm{pH} 7.5$ for Cp12 $\beta-\mathrm{HSDH}$, and 343 reported as $\mathrm{pH} 7.8$ for the crude native enzyme from strain D 762-06. ${ }^{20}$ Further work will be needed 344 to determine if distinct bile acid $12 \beta-\mathrm{HSDHs}$ are present in $C$. paraputrificum strains. Cp12 $\beta$-HSDH exhibited a dimeric quaternary structure by size-exclusion chromatography under our experimental conditions. Although future crystallization of Cp12 $\beta$-HSDH would better

347 illustrate its true polymeric state, HSDHs are often either tetrameric ${ }^{42,53}$ or dimeric. ${ }^{54,55} \mathrm{Cp} 12 \beta$ 348 HSDH was more specific for bile acids lacking a position 7-hydroxyl group: epiDCA and 12oxoLCA, over epiCA and 12-oxoCDCA. Cp12ß-HSDH also had lower activity with 3,12dioxoLCA versus 12-oxoLCA. This indicates that both the 7-hydroxyl and 3-oxo groups hinder

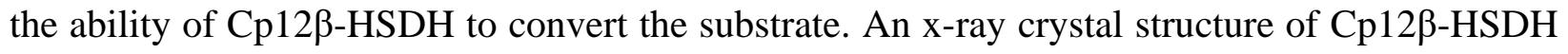
may shed light on why this apparent steric hindrance occurs.

Phylogenetic analysis of Cp12 $\beta$-HSDH coupled with synthetic biological "sampling" and

354 validation at different points along the branches revealed shared $12 \beta-\mathrm{HSDH}$ function among 355 Eisenbergiella sp. OF01-20 and Olsenella sp. GAM18, lending functional credibility to sequences 356 throughout the subtree (Figure 5; Table 2). Eisenbergiella sp. OF01-20 was originally sequenced 357 from a human gut microbiota cultivation project (Integrated Microbial Genomes [IMG] Genome ID: 2840324701). Eisenbergiella spp. are often present at relative abundances of less than $0.1 \%$ in

359 human fecal samples. ${ }^{56,57}$ Olsenella sp. GAM18 was initially isolated from humans (IMG Genome 360 ID: 2841219092). The relative abundance of Olsenella was shown to be about $2 \%$ within the gut 
361 microbiome of some individuals. ${ }^{58}$ Our subtree includes more abundant gut taxa such as

362 Ruminococcus (relative abundance $\sim 5 \%)^{59,60}$ and Collinsella (relative abundance $\sim 8 \%$ ) ${ }^{59}$, as well.

363 Due to limitations in $16 \mathrm{~S}$ rDNA sequencing depth, it is difficult to conclude if the species in our

364 subtree are found at relevant levels in the human gut or if $12 \beta-\mathrm{HSDH}$ genes are present. Therefore,

365 we performed a HMM search to assess the relative prevalence of $12 \beta-\mathrm{HSDH}$ genes. About $30 \%$

366 of subjects had putative $12 \beta-H S D H$ genes, indicating the relevance of this gene in the human gut

367 microbiome. The HMM search revealed that 220 microbial genomes out of 16,936 total contained

368 putative $12 \beta$-HSDH genes. While concrete prevalence is difficult to establish, putative $12 \beta-\mathrm{HSDH}$

369 genes are less widespread than the ubiquitous bile-acid metabolizing gene, bile salt hydrolase ${ }^{4}$,

370 which was present in 2,456/16,936 total genomes in these cohorts. These data expand the limited

371 metagenomic work that has focused on bile acid HSDH genes in the human gut. ${ }^{61}$

372 Two organisms from our $12 \beta-\mathrm{HSDH}$ subtree were also identified in a previous $12 \alpha-\mathrm{HSDH}$

373 phylogeny from Doden et al. (2018). Putative proteins WP_009140706.1 (12ß-HSDH) and

374 WP_009141301.1 (12 $\alpha-\mathrm{HSDH})$ are both present in Collinsella tanakaei YIT 12063 and are

375 encoded by the genes HMPREF9452_RS03390 and HMPREF9452_RS06335, respectively.

376 Similarly, Collinsella stercoris DSM 13279 encodes both putative 12ß-HSDH (WP_006720039.1;

377 COLSTE_RS01465) and 12 $\alpha-$ HSDH (WP_040360544.1; COLSTE_RS02900). ${ }^{10}$ Although the

378 dual $12 \alpha / 12 \beta-H S D H$ activity is untested in culture, we predict these strains are novel C-12

379 epimerizers. Epimerizing strains have been identified for the C-3 ${ }^{19,41}$ and C-7 hydroxyl $1^{1,62}$

380 positions, however, this is the first indication of bacteria capable of C-12 epimerization.

381 The sequence WP_007678535.1 from Novosphingobium sp. AP12, whose recombinant

382 enzyme product did not exhibit bile acid $12 \beta-\mathrm{HSDH}$ activity with the substrates tested, may be

383 specific for aerobic bile acid degradation products. Environmental microorganisms, such as 
Comamonas testosteroni TA441 and Pseudomonas sp. strain Chol1, encode a CA degradation pathway involving conversion of a 12-oxo-intermediate to $7 \alpha, 12 \beta$-dihydroxy-androsta-1,4-diene3,17 -dione (12ß-DHADD). ${ }^{63,64}$ Thus, sequences in the extension of the subtree may have $12 \beta$ HSDH activity, but with specificity for side-chain cleaved steroids rather than bile acids. and Actinobacteria. ${ }^{1}$ Bile acid $12 \alpha-\mathrm{HSDH}$ activity has been detected in Eggerthella species $^{15,52}$ in the phylum Actinobacteria and various clostridia ${ }^{10-12,36}$ in the phylum Firmicutes. Similarly, $3 \alpha-$ and $3 \beta-H S D H$ are widespread among Firmicutes ${ }^{1,65}$, and $3 \alpha-H S D H$ has also been reported in 392 Eggerthella species. ${ }^{13,15,41} 7 \alpha$ - and $7 \beta-\mathrm{HSDH}$ were shown in numerous Firmicutes ${ }^{14,37,65}$ and the 393 Actinobacteria Collinsella aerofaciens. ${ }^{25}$ Along with these bile acid-specific HSDHs, the 394 glucocorticoid $20 \alpha$ - and $20 \beta$-HSDHs are evident in both Firmicutes ${ }^{43,45}$ and Actinobacteria such as Bifidobacterium adolescentis ${ }^{66}$. Until this study, there were no reports of genes encoding $12 \beta$ -

HSDH and the activity had only been shown in C. paraputrificum, C. tertium and C. difficile. ${ }^{19}$

397 Thus, our phylogenetic analysis revealed hitherto unknown diversity for bile acid 12 $\beta$-HSDHs 398 within the Firmicutes and Actinobacteria. Bacteroidetes sequences were notably absent within our 399 12 $\beta$-HSDH subtree and only one sequence was identified in our HMM search, although 400 Bacteroidetes have been shown to encode multiple other HSDHs. ${ }^{1,49}$ Interestingly, C. tertium and 401 C. difficile enzymes were also not present in our phylogenetic analysis even though this activity 402 has been reported for strains of these clostridia ${ }^{19}$, indicating that genes encoding other forms of 403 bile acid 12 $\beta-\mathrm{HSDH}$ are present in the gut microbiome. The distribution pattern of microbial HSDHs is becoming increasingly clear (Figures $\mathbf{5} \&$ 405 7), although in many cases the evolutionary pressures on gut microbes for encoding particular 406 regio- and stereospecific HSDH enzymes is not clear. As observed with BSH enzymes, the 
407 functional importance of HSDHs may be strain-dependent. In some strains, the mere ability to

408 acquire or dispose of reducing equivalents may be important, and the class of enzyme unimportant.

409 Bile acid hydroxylation patterns affect the binding and activation/inhibition of host nuclear

410 receptors. ${ }^{67}$ HSDH enzymes may thus act in interkingdom-signaling, a hypothesis that has recent

411 support based on the effect of oxidized and epimerized bile acids on the function of regulatory $\mathrm{T}$

412 cells. $^{68,69}$

413 The concerted action of pairs of HSDHs result in bile acid products with reduced toxicity

414 for microbes expressing the HSDH(s) or for an important inter-species partner, which was likely

415 a factor in the evolution of these enzymes. Examples of strains of species capable of epimerizing

416 bile acid hydroxyl groups are found in the literature, and the physicochemical properties and

417 reduced toxicity of $\beta$-hydroxy bile acids are known, providing hypotheses for physiological

418 function. Clostridium limosum (now Hathewaya limosa) expresses both bile acid-inducible

419 NADP-dependent $7 \alpha-$ and $7 \beta-H S D H$ capable of converting CDCA to UDCA. ${ }^{70}$ CDCA is more

420 hydrophilic and more toxic to bacteria than UDCA. ${ }^{6,71}$ Indeed, treatment with UDCA increases the

421 hydrophilicity of the biliary pool, reducing cellular toxicity and improving biliary disorders. ${ }^{72}$

422 Similarly, strains of Eggerthella lenta ${ }^{15,41}$ and Ruminococcus gnavus ${ }^{41}$ express both NADPH-

423 dependent $3 \alpha$ - and $3 \beta$-HSDHs capable of forming $3 \beta$-bile acids (iso-bile acids). Iso-bile acids are

424 also more hydrophilic and less toxic to bacteria than the $\alpha$-hydroxy isomers. ${ }^{41}$ At least some strains

425 of $R$. gnavus also express NADPH-dependent 7 $\beta-\mathrm{HSDH}$, contributing to the epimerization of

426 CDCA to UDCA. ${ }^{39}$ It may be speculated that $R$. gnavus HSDHs function in detoxification of

427 hydrophobic bile acids such as CDCA and DCA; however, further work is needed. Analogous to

428 E. lenta and R. gnavus, C. paraputrificum is another example of a strain encoding multiple HSDHs

429 that favor formation of $\beta$-hydroxy bile acids. ${ }^{19}$ C. paraputrificum strains encode the iso-bile acid 
430 pathway as well as NADPH-dependent $12 \beta-H S D H .{ }^{19,20}$ While little is known about the biological

431 effects of $12 \beta$-bile acids (epi-bile acids), the physicochemical properties relative to $12 \alpha$-hydroxy

432 bile acids should approximate that of iso- and urso-derivatives. ${ }^{6,41,71}$ An important question

433 emerging from these observations is whether one particular epimeric product rather than another

434 has important consequences on the fitness of the bacterium generating them, or if the increased

435 hydrophilicity and reduced toxicity are the key factors.

436 Since the initial detection of epi-bile acids by Eneroth et. al. and Ali et. al. ${ }^{16-18}$, the

437 measurement of bile acid metabolomes in clinical samples has become commonplace ${ }^{73}$, yet few

438 studies measure or report epi-bile acids. Recently, 12ß-hydroxy and 12-oxo-bile acids have been

439 quantified in human feces by Franco et. al. (2019). 12-oxoLCA was the most abundant oxo-bile

440 acid in feces at concentrations of about one half that of DCA in stool. While epiDCA itself was

441 not measured, 3-oxo-12 $\beta$-hydroxy-CDCA was shown at $12 \pm 4 \mu \mathrm{g} / \mathrm{g}$ wet feces. ${ }^{74}$ Additionally,

442 epiDCA has been reported in biliary bile of angelfish, likely produced from bacterial origin, so the

443 12 $\beta$-HSDH gene may be widespread among resident microbiota of diverse vertebrate taxa. ${ }^{75} \mathrm{~A}$

444 critical limitation to the study of epi-bile acids is the absence of commercially available standards,

445 although there are methods available for chemical synthesis. ${ }^{76,77}$ The newly identified bile acid

$44612 \beta-H S D H s$ could be employed for the enzymatic production of epi-bile acid standards from oxo-

447 intermediates.

448 The physiological effects of epi-bile acids are poorly characterized, particularly in the GI

449 tract. Borgström and colleagues compared infusion of CA, ursoCA, and epiCA on bile flow, lipid

450 secretion, bile acid synthesis, and bile micellar formation. In contrast to ursoCA and CA, epiCA

451 was secreted into bile in an unconjugated form. The 12 $\beta$-hydroxyl group may hinder the enzyme

452 responsible for conjugation. Additionally, epiCA infusion increased the rate of secretion of newly 
453 synthesized bile salts. ${ }^{78}$ Another study reported increased 12-oxoLCA levels in rats with high

454 tumor incidence when they were fed a high safflower oil or corn oil diet.(Reddy 1984) While the

455 toxicity of epi-bile acids has not yet been tested relative to the secondary bile acids DCA or LCA,

456 both 12-oxoLCA and epiDCA are less hydrophobic than DCA by LC-MS (Figures 2 \& 3). Due

457 to the involvement of DCA in cancers of the liver and colon ${ }^{7,8}$, bile acid $12 \beta-\mathrm{HSDH}$ may be of

458 therapeutic importance in modulating the bile acid pool in favor of epiDCA over toxic DCA.

459 Future studies with animal models will be imperative to determine the effects of epi-bile acids on

460 host physiology.

461

462 Materials and methods

463 Bacterial strains and chemicals

464 Clostridium paraputrificum ATCC 25780 and Clostridium scindens ATCC 35704 were

465 obtained from $80^{\circ} \mathrm{C}$ glycerol stocks from culture collections at the University of Illinois Urbana-

466 Champaign (UIUC). E. coli DH5a (Turbo) competent cells from New England Biolabs (Ipswich,

467 MA) and NovaBlue GigaSingles ${ }^{\text {TM }}$ Competent cells from Novagen (San Diego, CA, USA) were

468 used for cloning, and E. coli BL21-Codon-Plus (DE3) RIPL was purchased from Stratagene (La

469 Jolla, CA, USA) and used for protein overexpression. 5 $\beta$-Cholanic acid-3 $\alpha, 7 \alpha, 12 \alpha$-triol (CA),

$4705 \beta$-cholanic acid-3 $\alpha, 12 \alpha$-diol (DCA), and 5 $\beta$-cholanic acid-3 $\alpha, 7 \alpha$-diol (CDCA) were purchased

471 from Sigma-Aldrich (St. Louis, MO, USA). Authentic $5 \beta$-cholanic acid-3 $\alpha, 12 \beta$-diol (epiDCA) and

$4725 \beta$-cholanic acid-3 $\alpha, 7 \alpha, 12 \beta$-diol (epiCA) were generously obtained from Lee R. Hagey

473 (University of California, San Diego). Other bile acids were purchased from Steraloids (Newport,

474 RI, USA). All other reagents were of the highest possible purity and purchased from Fisher

475 Scientific (Pittsburgh, PA, USA). 
Whole cell bile acid conversion assay

C. paraputrificum ATCC 25780 and C. scindens ATCC 35704 were cultivated in anaerobic

483 bile acid products from bacterial culture. Waters tC18 vacuum cartridges (3 cc) (Milford, MA, 484 USA) were preconditioned with $6 \mathrm{~mL} \mathrm{100 \%} \mathrm{hexanes,} 3 \mathrm{~mL} \mathrm{100 \%}$ acetone, $6 \mathrm{~mL} \mathrm{100 \%} \mathrm{methanol,}$ and $6 \mathrm{~mL}$ water $(\mathrm{pH} 3.0)$. The conditioned medium was added to the cartridges and vacuum was applied to pull media through dropwise. Cartridges were washed with $6 \mathrm{~mL}$ water $(\mathrm{pH} 3.0)$ and

$48740 \%$ methanol. Bile acid products were eluted with $3 \mathrm{~mL} 100 \%$ methanol. Eluates were then 488 evaporated under nitrogen gas and the residues dissolved in $200 \mu \mathrm{L} 100 \%$ methanol for LC-MS 489 analysis.

\section{Liquid chromatography-mass spectrometry}

LC-MS analysis for all samples was performed using a Waters Acquity UPLC system

493 coupled to a Waters SYNAPT G2-Si ESI mass spectrometer (Milford, MA, USA). LC was

494 performed with a Waters Acquity UPLC HSS T3 C18 column (1.8 $\mu \mathrm{m}$ particle size, $2.1 \mathrm{~mm}$ x 100

$495 \mathrm{~mm})$ at a column temperature of $40^{\circ} \mathrm{C}$. Samples were injected at $1 \mu \mathrm{L}$. Mobile phase A was water

496 and B was acetonitrile. The mobile phase gradient was as follows: 0 min 100\% mobile phase A,

$497 \quad 0.5 \min 100 \%$ A, $25 \min 0 \%$ A, $25.1 \min 100 \%$ A, $28 \min 100 \%$ A. The flow rate was $0.5 \mathrm{~mL} / \mathrm{min}$.

498 MS was carried out in negative ion mode with a desolvation temperature of $300^{\circ} \mathrm{C}$ and desolvation 
gas flow of $700 \mathrm{~L} / \mathrm{hr}$. The capillary voltage was $3,000 \mathrm{~V}$. Source temperature was $100^{\circ} \mathrm{C}$ and cone

500 voltage was $30 \mathrm{~V}$. Chromatographs and mass spectrometry data were analyzed using Waters

501 MassLynx software (Milford, MA, USA).

502

\section{Isolation of genomic DNA}

Genomic DNA was extracted from C. paraputrificum ATCC 25780 using the Fast DNA isolation kit from Mo-Bio (Carlsbad, CA, USA) according to the manufacturer's protocol for polymerase chain reaction and molecular cloning applications.

\section{Heterologous expression of potential 12ß-HSDH proteins}

The pET-28a(+) and pET-46 Ek/LIC vectors were obtained from Novagen (San Diego, generated by PCR amplification with cloning primers from Integrative DNA Technologies

512 (Coralville, IA, USA) of C. paraputrificum ATCC 25780 genomic DNA or genes synthesized in

513 E. coli $\mathrm{K} 12$ codon usage (IDT, Coralville, IA, USA). Cloning primers and genes created by gene

514 synthesis are listed in Table S1. Inserts were amplified using the Phusion High Fidelity

515 Polymerase (Stratagene, La Jolla, CA, USA) and cloned into pET-28a(+) after insert and vector

516 were double digested with the appropriate restriction endonuclease and treated with DNA Ligase,

517 or annealed into pET-46 Ek/LIC after treatment with T4 DNA Polymerase. Recombinant plasmids

518 were transformed via heat shock method, plated, and grown overnight at $37^{\circ} \mathrm{C}$ on lysogeny broth

519 (LB) agar plates supplemented with antibiotic $(50 \mu \mathrm{g} / \mathrm{mL}$ kanamycin or $100 \mu \mathrm{g} / \mathrm{mL}$ ampicillin).

520 Vectors were either transformed into chemically competent E. coli DH5 $\alpha$ cells and grown with

521 kanamycin $(\mathrm{pET}-28 \mathrm{a}(+))$ or transformed into NovaBlue GigaSingles ${ }^{\mathrm{TM}}$ Competent cells and 
grown with ampicillin (pET-46 Ek/LIC). A single colony from each transformation was inoculated

523 into LB medium (5 mL) containing the corresponding antibiotic and grown to saturation.

524 Recombinant plasmids were extracted from cell pellets using the QIAprep Spin Miniprep kit

525 (Qiagen, Valencia, CA, USA). The sequence of the inserts was confirmed by Sanger sequencing

526 (W. M. Keck Center for Comparative and Functional Genomics at the University of Illinois at

527 Urbana-Champaign).

For protein expression, the extracted recombinant plasmids were transformed into E. coli

BL-21 CodonPlus (DE3) RIPL chemically competent cells by heat shock method and cultured medium supplemented with antibiotics and grown at $37^{\circ} \mathrm{C}$ for 6 hours with vigorous aeration. The pre-cultures were added to fresh LB medium (1 L), supplemented with antibiotics, and aerated at $37^{\circ} \mathrm{C}$ until reaching an $\mathrm{OD}_{600 \mathrm{~nm}}$ of 0.3 . IPTG was added to each culture at a final concentration of pelleted and resuspended in binding buffer $(20 \mathrm{mM}$ Tris- $\mathrm{HCl}, 300 \mathrm{mM} \mathrm{NaCl}, 10 \mathrm{mM} 2-$ mercaptoethanol, $\mathrm{pH}$ 7.9). The cells were subjected to five passages through an EmulsiFlex C-3 cell homogenizer (Avestin, Ottawa, Canada), and the cell debris was separated by centrifugation.

541 protocol. The recombinant protein was eluted using an elution buffer composed of $20 \mathrm{mM}$ Tris-

$542 \mathrm{HCl}, 300 \mathrm{mM} \mathrm{NaCl}, 10 \mathrm{mM}$ 2-mercaptoethanol, and $250 \mathrm{mM}$ imidazole at $\mathrm{pH}$ 7.9. The resulting

543 purified protein was analyzed using sodium dodecyl sulfate-polyacrylamide gel electrophoresis

544 (SDS-PAGE). The observed subunit mass for each was calculated by migration distance of 
545 purified protein to standard proteins in ImageJ (https://imagej.nih.gov/ij/docs/faqs.html).

546 TMHMM v. 2.0 was used to predict transmembrane helices. ${ }^{22}$

548 Enzyme Assays

Pure recombinant $12 \beta-\mathrm{HSDH}$ reaction mixtures were made using $50 \mu \mathrm{M}$ substrate, $150 \mu \mathrm{M}$

550 cofactor and $10 \mathrm{nM}$ enzyme in $150 \mathrm{mM} \mathrm{NaCl}, 50 \mathrm{mM}$ sodium phosphate buffer at the pH optima

5517.0 or 7.5. Reactions were monitored by spectrophotometric assay measuring the oxidation or

552 reduction of $\mathrm{NADP}(\mathrm{H})$ aerobically at $340 \mathrm{~nm}\left(6,220 \mathrm{M}^{-1} \cdot \mathrm{cm}^{-1}\right)$ continuously for $1.5 \mathrm{~min}$ on a

553 NanoDrop 2000c UV-Vis spectrophotometer (Fisher Scientific, Pittsburgh, PA, USA) using a 10

$554 \mathrm{~mm}$ quartz cuvette (Starna Cells, Atascadera, CA, USA). Additional reactions were incubated

555 overnight at room temperature and extracted by vortexing with two volumes ethyl acetate twice.

556 The organic layer was recovered and evaporated under nitrogen gas. The products were dissolved

557 in $50 \mu \mathrm{L}$ methanol and LC-MS was performed as described above or used for thin layer 558 chromatography.

559 The buffers for investigation of the optimal $\mathrm{pH}$ of recombinant $12 \beta$-HSDH contained 150

$560 \mathrm{mM} \mathrm{NaCl}$ and one of the following buffering agents: $50 \mathrm{mM}$ sodium acetate ( $\mathrm{pH} 6.0), 50 \mathrm{mM}$

561 sodium phosphate $(\mathrm{pH} 6.5$ to 7.5$)$, and $50 \mathrm{mM}$ Tris-Cl (pH 8.0). Substrate specificity was

562 performed according to the above reaction conditions at the optimal $\mathrm{pH}$.

563 The reaction mixtures for kinetic analysis were $10 \mathrm{nM}$ enzyme, sodium phosphate buffer

564 (pH 7.0), and $150 \mu \mathrm{M}$ NADPH for varying concentrations of 12-oxoLCA or $80 \mu \mathrm{M}$ 12-oxoLCA

565 for varying NADPH concentrations in the reductive direction. The oxidative reaction mixture

566 contained $10 \mathrm{nM}$ enzyme, sodium phosphate buffer ( $\mathrm{pH} 7.5)$, and $300 \mu \mathrm{M} \mathrm{NADP}^{+}$when epiDCA

567 concentrations were changed or $100 \mu \mathrm{M}$ epiDCA when $\mathrm{NADP}^{+}$was varied. Kinetic parameters 
were estimated with GraphPad Prism (GraphPad Prism, La Jolla, CA, USA) to fit the data using nonlinear regression to the Michaelis-Menten equation.

\section{Thin layer chromatography}

Reaction mixtures were made using $50 \mu \mathrm{M}$ substrate, $150 \mu \mathrm{M}$ cofactor and $10 \mathrm{nM}$ enzyme layer was recovered and evaporated under nitrogen gas. The products were dissolved in $50 \mu \mathrm{L}$ methanol and spotted on a TLC plate (silica gel IB2-F flexible TLC sheet, 20 x $20 \mathrm{~cm}, 250 \mu \mathrm{m}$ analytical layer; J. T. Baker, Avantor Performance Materials, LLC, PA, USA). The steroids were separated with a 70:20:2 toluene-1,4-dioxane-acetic acid mobile phase and visualized using a $10 \%$ phosphomolybdic acid in ethanol spray and heating for $15 \mathrm{~min}$ at $100^{\circ} \mathrm{C} .^{79}$

Native molecular weight determination

Size-exclusion chromatography was performed using a Superose 6 10/300 GL analytical column (GE Healthcare, Piscataway, NJ, USA) connected to an ÄKTAxpress chromatography molecular mass of $12 \beta-\mathrm{HSDH}$ was determined by comparing its elution volume to that of Gel

588 Filtration Standard proteins (Bio-Rad, Hercules, CA, USA): thyroglobulin, $\gamma$-globulin, ovalbumin, 589 myoglobin, vitamin $\mathrm{B}_{12}$. 


\section{Phylogenetic Analysis}

The sequence of the $C$. paraputrificum $12 \beta-\mathrm{HSDH}$ protein (accession number

593 WP_027099077.1) was used as query for a similarity search against the NCBI non-redundant

594 protein database by BLASTP ${ }^{80}$, with a maximum E-value threshold of $1 \mathrm{e}-10$ and a limit of 5,000

595 results. Retrieved sequences were aligned with Muscle v. 3.8.1551 ${ }^{81}$ and analyzed by maximum

596 likelihood with RAxML v. 8.2.11. ${ }^{82}$ Selection of the best-fitting amino acid substitution model and

597 number of bootstrap pseudoreplicates were performed automatically, and substitution rate

598 heterogeneity was modeled with gamma distributed rate categories. The resulting phylogenetic

599 tree was formatted by Dendroscope v. 3.5.10 ${ }^{83}$ and further cosmetic modifications were performed

600 with the vector editor Inkscape, v. 0.92 .4 (https://inkscape.org).

$601 \quad$ For closer analysis of the phylogenetic affiliation of C. paraputrificum ATCC $2578012 \beta-$

602 HSDH, sequences from the well-supported subtree where this sequence is located in the 5,000-

603 sequence tree, plus an outgroup, were reanalyzed for confirming the relative placement of all

604 sequences nearest to Cp12 $\beta$-HSDH. The methods used were the same as described above for the 605 full tree.

606 A maximum-likelihood tree of representative HSDH sequences was inferred by selecting 607 sequences from each HSDH subfamily, based on the tree from Mythen et al. $(2018)^{15}$, with the 608 addition of eukaryotic, archaeal, and other bacterial sequences deposited in the public databases. 609 Phylogenetic inference methods were the same as described above.

\section{Hidden Markov Model Search}

A Hidden Markov Model (HMM) search was performed using a custom HMM profile

613 against a concatenated file of metagenome assembled genomes (MAGs) from four publicly 
614 available cohorts. ${ }^{30-33}$ MAGs were filtered for genome completeness, quality, and contamination

615 as described. ${ }^{84}$ For generation of the custom $12 \beta$-HSDH profile, reference sequences from the $12 \beta$ -

616 HSDHs characterized in this paper were aligned with MAFFT, manually trimmed, and constructed

617 using hmmscan. ${ }^{85}$ The MAG database was searched using HMMSearch version $3.3 .0^{85}$, using an

618 individually identified cut-off of 350.00. Resulting hits were then filtered to remove results less

619 than $70 \%$ completeness and closest matched species were recorded. The HMM search file is

620 publicly available at: https://github.com/AnantharamanLab/doden_et_al_2021.

\section{Acknowledgments}

623 We gratefully acknowledge support to J.M.R. for this work by the National Cancer Institute grant

624 1RO1 CA204808-01, as well as USDA Hatch ILLU-538-916 and Illinois Campus Research Board

625 RB18068. H.L.D. is supported by the David H. and Norraine A. Baker Graduate Fellowship in

626 Animal Sciences. We would like to express our very great appreciation to Dr. Lee R. Hagey for

627 providing the critical substrates epiDCA and epiCA.

\section{Disclosure of Potential Conflicts of Interest}

630 No potential conflicts of interest.

\section{References}

633 1. Ridlon JM, Kang D-J, Hylemon PB. Bile salt biotransformations by human intestinal

634 bacteria. J Lipid Res 2006; 47:241-59.

635 2. Vlahcevic ZR, Heuman DM, Hylemon PB. Physiology and pathophysiology of

636 enterohepatic circulation of bile acids. In: Zakim D, Boyer T, editors. Hepatology: A 
Textbook of Liver Disease. Philadelphia: Saunders; 1996. page 376-417.

638 3. Dawson PA, Karpen SJ. Intestinal transport and metabolism of bile acids. J Lipid Res 2015; 56:1085-99.

640 4. Jones B V., Begley M, Hill C, Gahan CGM, Marchesi JR. Functional and comparative metagenomic analysis of bile salt hydrolase activity in the human gut microbiome. Proc Natl Acad Sci U S A 2008; 105:13580-5.

5. Ridlon JM, Harris SC, Bhowmik S, Kang DJ, Hylemon PB. Consequences of bile salt biotransformations by intestinal bacteria. Gut Microbes 2016; 7:22-39.

6. Watanabe M, Fukiya S, Yokota A. Comprehensive evaluation of the bactericidal activities of free bile acids in the large intestine of humans and rodents. J Lipid Res 2017; 58:1143-

7. Bernstein C, Holubec H, Bhattacharyya AK, Nguyen H, Payne CM, Zaitlin B, Bernstein H. Carcinogenicity of deoxycholate, a secondary bile acid. Arch Toxicol 2011; 85:86371.

8. Yoshimoto S, Loo TM, Atarashi K, Kanda H, Sato S, Oyadomari S, Iwakura Y, Oshima K, Morita H, Hattori M, et al. Obesity-induced gut microbial metabolite promotes liver cancer through senescence secretome. Nature 2013; 499:97-101.

654 9. Wu JT, Gong J, Geng J, Song YX. Deoxycholic acid induces the overexpression of intestinal mucin, MUC2, via NF-kB signaling pathway in human esophageal adenocarcinoma cells. BMC Cancer 2008; 8:1-10. of oxo-bile acids and characterization of recombinant $12 \alpha$-hydroxysteroid dehydrogenases from bile acid 7 $\alpha$-dehydroxylating human gut bacteria. Appl Environ Microbiol 2018; 
661 11. Macdonald IA, Jellett JF, Mahony DE. 12alpha-Hydroxysteroid dehydrogenase from Clostridium group P strain C48-50 ATCC \#29733: partial purification and characterization. J Lipid Res 1979; 20:234-9.

664 12. Harris JN, Hylemon PB. Partial purification and characterization of NADP-dependent 12 $\alpha$-hydroxysteroid dehydrogenase from Clostridium leptum. Biochim Biophys Acta

667 13. Macdonald IA, Jellett JF, Mahony DE, Holdeman L V. Bile salt $3 \alpha-$ and $12 \alpha-$ hydroxysteroid dehydrogenases from Eubacterium lentum and related organisms. Appl Environ Microbiol 1979; 37:992-1000.

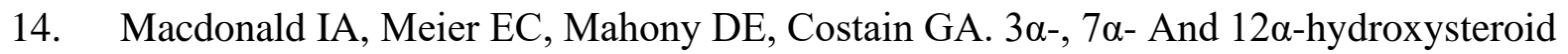
dehydrogenase activities from Clostridium perfringens. Biochim Biophys Acta 1976; 450:142-53.

673 15. Mythen SM, Devendran S, Méndez-García C, Cann I, Ridlon JM. Targeted synthesis and characterization of a gene cluster encoding NAD(P)H-dependent $3 \alpha-, 3 \beta$-, and $12 \alpha-$ hydroxysteroid dehydrogenases from Eggerthella CAG:298, a gut metagenomic sequence.

677 16. Ali SS, Kuksis A, Beveridge JM. Excretion of bile acids by three men on corn oil and butterfat diets. Can J Biochem 1966; 44:1377-88.

679 17. Ali SS, Kuksis A, Beveridge JM. Excretion of bile acids by three men on a fat-free diet. Can J Biochem 1966; 44:957-69.

681 18. Eneroth P, Gordon B, Ryhage R, Sjövall J. Identification of mono- and dihydroxy bile acids in human feces by gas-liquid chromatography and mass spectrometry. J Lipid Res 
1966; 7:511-23.

684 19. Edenharder R, Schneider J. 12ß-Dehydrogenation of bile acids by Clostridium paraputrificum, C. tertium, and C. difficile and epimerization at carbon-12 of deoxycholic acid by cocultivation with $12 \alpha$-dehydrogenating Eubacterium lentum. Appl Environ Microbiol 1985; 49:964-8.

20. Edenharder R, Pfützner A. Characterization of NADP-dependent 12 $\beta$-hydroxysteroid dehydrogenase from Clostridium paraputrificum. Biochim Biophys Acta 1988; 962:36270.

21. Penning TM. Human hydroxysteroid dehydrogenases and pre-receptor regulation: Insights into inhibitor design and evaluation. J Steroid Biochem Mol Biol 2011; 125:46-56.

22. Krogh A, Larsson B, Von Heijne G, Sonnhammer ELL. Predicting transmembrane protein topology with a hidden Markov model: Application to complete genomes. J Mol Biol

23. Kiu R, Caim S, Alcon-Giner C, Belteki G, Clarke P, Pickard D, Dougan G, Hall LJ.

24. Muñoz M, Restrepo-Montoya D, Kumar N, Iraola G, Herrera G, Ríos-Chaparro DI, DíazArévalo D, Patarroyo MA, Lawley TD, Ramírez JD. Comparative genomics identifies potential virulence factors in Clostridium tertium and C. paraputrificum. Virulence 2019; 10:657-76.

25. Liu L, Aigner A, Schmid RD. Identification, cloning, heterologous expression, and characterization of a NADPH-dependent 7 $\beta$-hydroxysteroid dehydrogenase from 
Collinsella aerofaciens. Appl Microbiol Biotechnol 2011; 90:127-35.

707

708

709

710

711

712

713

714

715

716

717

718

719

720

721

722

723

724

725

726

727

728

26. Wegner K, Just S, Gau L, Mueller H, Gérard P, Lepage P, Clavel T, Rohn S. Rapid analysis of bile acids in different biological matrices using LC-ESI-MS/MS for the investigation of bile acid transformation by mammalian gut bacteria. Anal Bioanal Chem 2017; 409:1231-45.

27. Sohn JH, Kwon KK, Kang JH, Jung HB, Kim SJ. Novosphingobium pentaromativorans sp. nov., a high-molecular-mass polycyclic aromatic hydrocarbon-degrading bacterium isolated from estuarine sediment. Int J Syst Evol Microbiol 2004; 54:1483-7.

28. Hashimoto T, Onda K, Morita T, Luxmy BS, Tada K, Miya A, Murakami T. Contribution of the estrogen-degrading bacterium Novosphingobium sp. strain JEM-1 to estrogen removal in wastewater treatment. J Environ Eng 2010; 136:890-6.

29. Gan HM, Hudson AO, Rahman AYA, Chan KG, Savka MA. Comparative genomic analysis of six bacteria belonging to the genus Novosphingobium: Insights into marine adaptation, cell-cell signaling and bioremediation. BMC Genomics 2013; 14:431.

30. Yu J, Feng Q, Wong SH, Zhang D, Yi Liang Q, Qin Y, Tang L, Zhao H, Stenvang J, Li Y, et al. Metagenomic analysis of faecal microbiome as a tool towards targeted non-invasive biomarkers for colorectal cancer. Gut 2017; 66:70-8.

31. Zeller G, Tap J, Voigt AY, Sunagawa S, Kultima JR, Costea PI, Amiot A, Böhm J, Brunetti F, Habermann N, et al. Potential of fecal microbiota for early-stage detection of colorectal cancer. Mol Syst Biol 2014; 10:1-18.

32. Vogtmann E, Hua X, Zeller G, Sunagawa S, Voigt AY, Hercog R, Goedert JJ, Shi J, Bork P, Sinha R. Colorectal cancer and the human gut microbiome: Reproducibility with whole-genome shotgun sequencing. PLoS One 2016; 11:e0155362. 
33. Feng Q, Liang S, Jia H, Stadlmayr A, Tang L, Lan Z, Zhang D, Xia H, Xu X, Jie Z, et al. Gut microbiome development along the colorectal adenoma-carcinoma sequence. Nat Commun 2015; 6:1-13.

34. Chung WSF, Meijerink M, Zeuner B, Holck J, Louis P, Meyer AS, Wells JM, Flint HJ, Duncan SH. Prebiotic potential of pectin and pectic oligosaccharides to promote antiinflammatory commensal bacteria in the human colon. FEMS Microbiol Ecol 2017; 93:1-

35. Liu S, Zhao W, Liu X, Cheng L. Metagenomic analysis of the gut microbiome in atherosclerosis patients identify cross-cohort microbial signatures and potential

36. Aigner A, Gross R, Schmid R, Braun M, Mauer S. Novel 12 $\alpha$-hydroxysteroid dehydrogenases, production and use therof. 2011; :US patent 20110091921A1.

37. Baron SF, Franklund C V., Hylemon PB. Cloning, sequencing, and expression of the gene coding for bile acid $7 \alpha$-hydroxysteroid dehydrogenase from Eubacterium sp. strain VPI 12708. J Bacteriol 1991; 173:4558-69.

38. Yoshimoto T, Higashi H, Kanatani A, Lin XS, Nagai H, Oyama H, Kurazono K, Tsuru D. Cloning and sequencing of the $7 \alpha$-hydroxysteroid dehydrogenase gene from Escherichia coli HB101 and characterization of the expressed enzyme. J Bacteriol 1991; 173:2173-9.

747 39. Lee JY, Arai H, Nakamura Y, Fukiya S, Wada M, Yokota A. Contribution of the 7ßhydroxysteroid dehydrogenase from Ruminococcus gnavus N53 to ursodeoxycholic acid formation in the human colon. J Lipid Res 2013; 54:3062-9.

40. Ferrandi EE, Bertolesi GM, Polentini F, Negri A, Riva S, Monti D. In search of sustainable chemical processes: Cloning, recombinant expression, and functional 
characterization of the $7 \alpha$ - and $7 \beta$-hydroxysteroid dehydrogenases from Clostridium absonum. Appl Microbiol Biotechnol 2012; 95:1221-33.

754 41. Devlin AS, Fischbach MA. A biosynthetic pathway for a prominent class of microbiotaderived bile acids. Nat Chem Biol 2015; 11:685-90.

42. Doden HL, Pollet RM, Mythen SM, Wawrzak Z, Devendran S, Cann I, Koropatkin NM,

Ridlon JM. Structural and biochemical characterization of 20ß-hydroxysteroid dehydrogenase from Bifidobacterium adolescentis strain L2-32. J Biol Chem 2019; 294:12040-53.

43. Devendran S, Méndez-García C, Ridlon JM. Identification and characterization of a 20 $\beta$ HSDH from the anaerobic gut bacterium Butyricicoccus desmolans ATCC 43058. J Lipid Res 2017; 58:916-25.

44. Ridlon JM, Ikegawa S, Alves JMP, Zhou B, Kobayashi A, Iida T, Mitamura K, Tanabe G,

Serrano M, De Guzman A, et al. Clostridium scindens: a human gut microbe with a high potential to convert glucocorticoids into androgens. J Lipid Res 2013; 54:2437-49.

45. Bernardi R, Doden H, Melo M, Devendran S, Pollet R, Mythen S, Bhowmik S, Lesley S, Cann I, Luthey-Schulten Z, et al. Bacteria on steroids: the enzymatic mechanism of an NADH-dependent dehydrogenase that regulates the conversion of cortisol to androgen in

771 46. Fahrbach M, Kuever J, Meinke R, Kämpfer P, Hollender J. Denitratisoma oestradiolicum the gut microbiome. 2020; :bioRxiv 2020.06.12.149468. Available from: gen. nov., sp. nov., a 17 $\beta$-oestradiol-degrading, denitrifying betaproteobacterium. Int J

774 47. Ricaboni D, Mailhe M, Vitton V, Cadoret F, Fournier PE, Raoult D. 'Intestinibacillus 
massiliensis' gen. nov., sp. nov., isolated from human left colon. New Microbes New Infect 2017; 17:18-20.

48. Morris DJ, Ridlon JM. Glucocorticoids and gut bacteria: "The GALF Hypothesis" in the metagenomic era. Steroids 2017; 125:1-13.

49. Sherrod JA, Hylemon PB. Partial purification and characterization of NAD-dependent $7 \alpha-$ hydroxysteroid dehydrogenase from Bacteroides thetaiotaomicron. 1977; 486:351-8.

50. Edenharder R, Mielek K. Epimerization, oxidation and reduction of bile acids by Eubacterium lentum. Syst Appl Microbiol 1984; 5:287-98.

783 51. Snyder ML. The serologic agglutinatin of the obligate anaerobes Clostridium paraputrificum (Beinstock) and Clostridium capitovalis (Snyder and Hall). J Bacteriol

52. Harris SC, Devendran S, Méndez- García C, Mythen SM, Wright CL, Fields CJ, strains C592 and DSM 2243. Gut Microbes 2018; 9:523-39.

53. Filling C, Berndt KD, Benach J, Knapp S, Prozorovski T, Nordling E, Ladenstein R, Jörnvall H, Oppermann U. Critical residues for structure and catalysis in short-chain

54. Grimm C, Maseri E, Möbusi E, Klebe G, Reuter K, Ficner R. The crystal structure of $3 \alpha-$ hydroxysteroid dehydrogenase/carbonyl reductase from Comamonas testosteroni shows a novel oligomerization pattern within the short chain dehydrogenase/reductase family. J Biol Chem 2000; 275:41333-9.

55. Savino S, Ferrandi EE, Forneris F, Rovida S, Riva S, Monti D, Mattevi A. Structural and biochemical insights into $7 \beta$-hydroxysteroid dehydrogenase stereoselectivity. Proteins 
2016; 84:859-65.

799 56. Jang LG, Choi G, Kim SW, Kim BY, Lee S, Park H. The combination of sport and sportspecific diet is associated with characteristics of gut microbiota: An observational study. $\mathbf{J}$ Int Soc Sports Nutr 2019; 16:1-10.

57. Ma S, You Y, Huang L, Long S, Zhang J, Guo C, Zhang N, Wu X, Xiao Y, Tan H. Alterations in gut microbiota of gestational diabetes patients during the first trimester of pregnancy. Front Cell Infect Microbiol 2020; 10:1-14.

58. Amaruddin AI, Hamid F, Koopman JPR, Muhammad M, Brienen EAT, van Lieshout L, Geelen AR, Wahyuni S, Kuijper EJ, Sartono E, et al. The bacterial gut microbiota of schoolchildren from high and low socioeconomic status: A study in an urban area of Makassar, Indonesia. Microorganisms 2020; 8:1-12.

59. Doumatey AP, Adeyemo A, Zhou J, Lei L, Adebamowo SN, Adebamowo C, Rotimi CN. Gut microbiome profiles are associated with type 2 diabetes in urban africans. Front Cell Infect Microbiol 2020; 10:1-13.

60. Turpin W, Espin-Garcia O, Xu W, Silverberg MS, Kevans D, Smith MI, Guttman DS, Griffiths A, Panaccione R, Otley A, et al. Association of host genome with intestinal

815 61. Labbé A, Ganopolsky JG, Martoni CJ, Prakash S, Jones ML. Bacterial bile metabolising gene abundance in Crohn's, ulcerative colitis and type 2 diabetes metagenomes. PLoS One 2014; 9:e115175. 
821 63. Horinouchi M, Hayashi T, Koshino H, Malon M, Yamamoto T, Kudo T. Identification of genes involved in inversion of stereochemistry of a C-12 hydroxyl group in the catabolism of cholic acid by Comamonas testosteroni TA441. J Bacteriol 2008; 190:5545-54.

824 64. Holert J, Kulić Ž, Yücel O, Suvekbala V, Suter MJF, Möller HM, Philipp B. Degradation of the acyl side chain of the steroid compound cholate in Pseudomonas sp. strain Chol1 proceeds via an aldehyde intermediate. J Bacteriol 2013; 195:585-95.

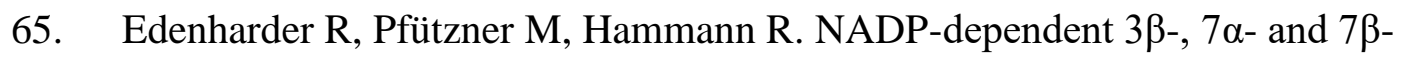
hydroxysteroid dehydrogenase activities from a lecithinase-lipase-negative Clostridium

66. Ridlon JM, Devendran S, Alves JM, Doden H, Wolf PG, Pereira G V., Ly L, Volland A, comparative genomics, metatranscriptomic, and bile acid metabolomics analysis of a defined microbial community in gnotobiotic mice. Gut Microbes 2020; 11:381-404.

67. Wahlström A, Kovatcheva-Datchary P, Ståhlman M, Bäckhed F, Marschall HU. Crosstalk between bile acids and gut microbiota and its impact on farnesoid X receptor signalling.

68. Song X, Sun X, Oh SF, Wu M, Zhang Y, Zheng W, Geva-Zatorsky N, Jupp R, Mathis D, 
dehydrogenases in Clostridium limosum. J Lipid Res 1985; 26:344-50.

845 71. Hofmann AF, Roda A. Physicochemical properties of bile acids and their relationship to biological properties: An overview of the problem. J Lipid Res 1984; 25:1477-89.

847 72. Goossens J, Bailly C. Ursodeoxycholic acid and cancer: From chemoprevention to chemotherapy. Pharmacol Ther 2019; 203:107396.

849 73. Liu Y, Rong Z, Xiang D, Zhang C, Liu D. Detection technologies and metabolic profiling of bile acids: A comprehensive review. Lipids Health Dis 2018; 17:121.

851 74. Franco P, Porru E, Fiori J, Gioiello A, Cerra B, Roda G, Caliceti C, Simoni P, Roda A. Identification and quantification of oxo-bile acids in human faeces with liquid chromatography-mass spectrometry: A potent tool for human gut acidic sterolbiome studies. J Chromatogr A 2019; 1585:70-81.

75. Hofmann AF, Hagey LR, Krasowski MD. Bile salts of vertebrates: Structural variation

77. Iida T, Momose T, Chang FC, Nambara T. Potential bile acid metabolites. XI. Syntheses of stereoisomeric 7,12-dihydroxy-5 $\alpha$-cholanic acids. Chem Pharm Bull 1986; 34:1934-8.

861 78. Borgström B, Barrowman J, Krabisch L, Lindström M, Lillienau J. Effects of cholic acid, 7 $\beta$-hydroxy- and 12 $\beta$-hydroxy-isocholic acid on bile flow, lipid secretion and bile acid synthesis in the rat. Scand J Clin Lab Invest 1986; 46:167-75.

864 79. Eneroth P. Thin-layer chromatography of bile acids. J Lipid Res 1963; 4:11-6.

865 80. Camacho C, Coulouris G, Avagyan V, Ma N, Papadopoulos J, Bealer K, Madden TL. 
867 81. Edgar RC. MUSCLE: Multiple sequence alignment with high accuracy and high

$868 \quad$ throughput. Nucleic Acids Res 2004; 32:1792-7.

869 82. Stamatakis A. RAxML version 8: A tool for phylogenetic analysis and post-analysis of

$870 \quad$ large phylogenies. Bioinformatics 2014; 30:1312-3.

871 83. Huson DH, Richter DC, Rausch C, Dezulian T, Franz M, Rupp R. Dendroscope: An

872 interactive viewer for large phylogenetic trees. BMC Bioinformatics 2007; 8:460.

873 84. Pasolli E, Asnicar F, Manara S, Zolfo M, Karcher N, Armanini F, Beghini F, Manghi P,

874 Tett A, Ghensi P, et al. Extensive unexplored human microbiome diversity revealed by

875 over 150,000 genomes from metagenomes spanning age, geography, and lifestyle. Cell

$876 \quad 2019 ; 176: 649-62$.

877 85. Eddy SR. Accelerated profile HMM searches. PLoS Comput Biol 2011; 7:e1002195. 

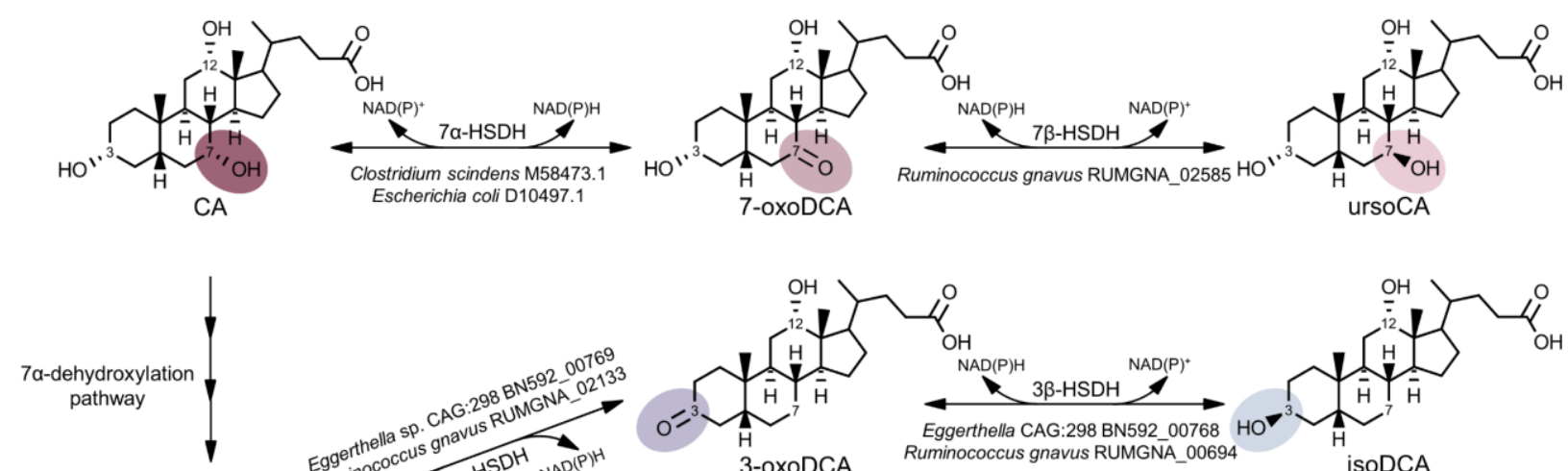

Figure 1. A gene encoding 12 $\beta$-HSDH completes the gut microbial epi-bile acid pathway.

Cholic acid (CA) is converted to the oxo-intermediate, 7-oxodeoxycholic acid (7-oxoDCA), and

further to ursoCA through the urso-bile acid pathway catalyzed by NAD(P)-dependent $7 \alpha$ - and $7 \beta$ HSDH. The secondary bile acid deoxycholic acid (DCA) is formed through the multi-step $7 \alpha-$ dehydroxylation of CA. DCA is biotransformed to 3 -oxoDCA by $3 \alpha-\mathrm{HSDH}$ and to isoDCA by $3 \beta-H S D H$ in the iso-bile acid pathway. DCA can be converted to 12-oxolithocholic acid (12oxoLCA) by $12 \alpha-\mathrm{HSDH}$ and from 12 -oxoLCA to epiDCA by $12 \beta-\mathrm{HSDH}$. Examples of bacteria expressing each HSDH are shown below the reaction followed by corresponding gene annotations. 
A. Clostridium paraputrificum ATCC 25780

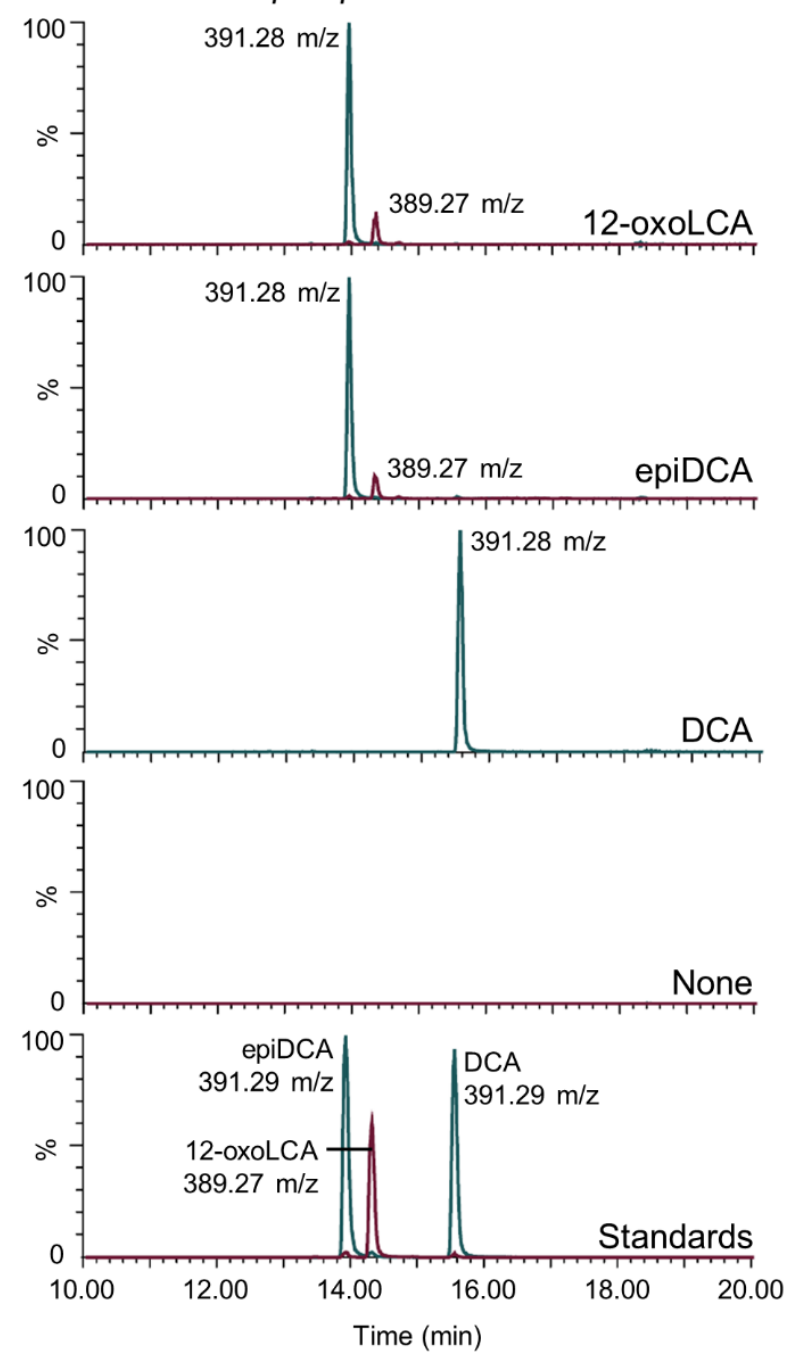

B. Clostridium scindens ATCC 35704
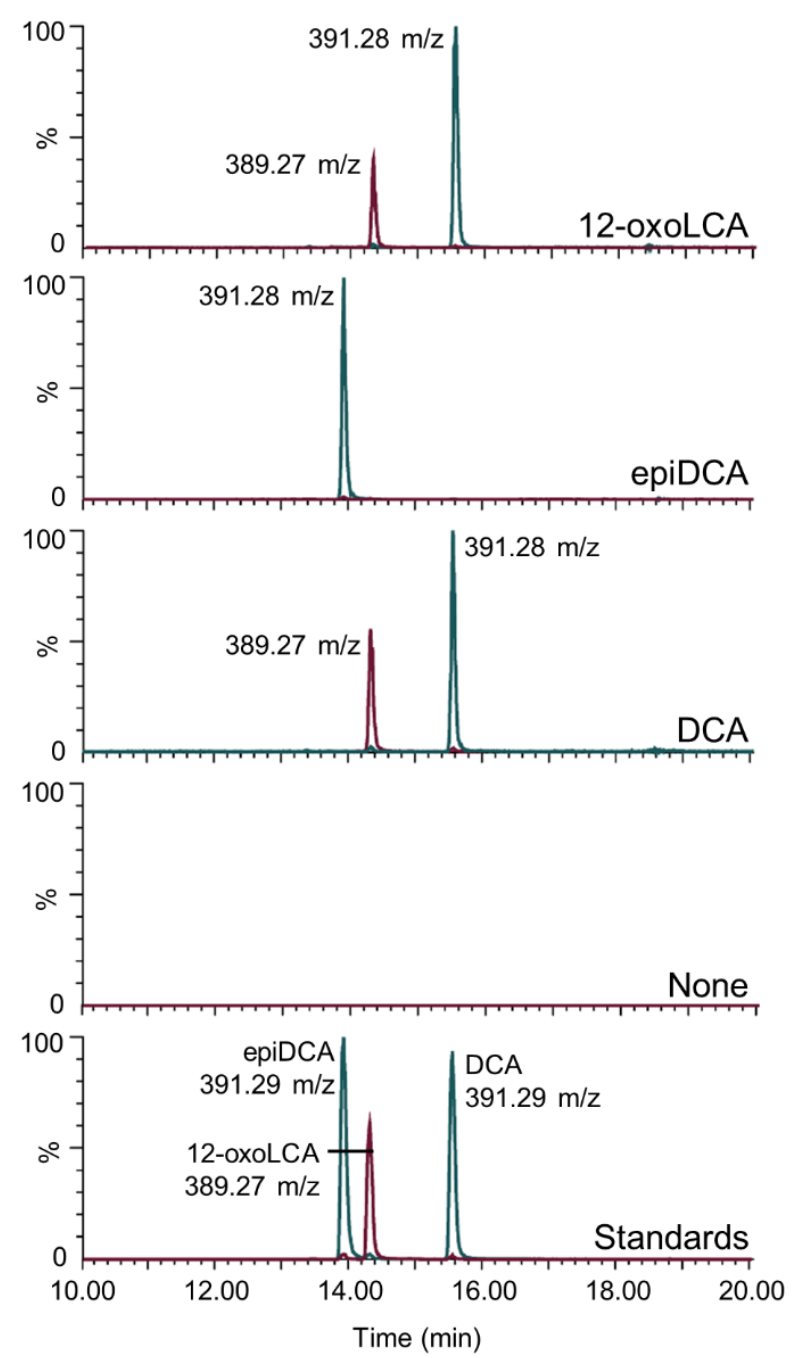

893 Figure 2. Clostridium paraputrificum ATCC 25780 expresses 12ß-HSDH while $C$. scindens

894 ATCC 35704 expresses 12a-HSDH by whole-cell LC-MS. (A) Representative negative ion

895 mode LC-MS chromatograms in single ion monitoring mode overlaid with linked vertical axes of C. paraputrificum reaction products from $50 \mu \mathrm{M}$ substrate compared to deoxycholic acid (DCA),

897 12-oxolithocholic acid (12-oxoLCA) and epiDCA standards. (B) As a control, representative 898 negative ion mode LC-MS chromatograms in single ion monitoring mode overlaid with linked 899 vertical axes of $C$. scindens products from $50 \mu \mathrm{M}$ substrate was used to demonstrate $12 \alpha-\mathrm{HSDH}$ 
bioRxiv preprint doi: https://doi.org/10.1101/2020.09.27.315549; this version posted February 26, 2021. The copyright holder for this preprint

(which was not certified by peer review) is the author/funder, who has granted bioRxiv a license to display the preprint in perpetuity. It is made available under aCC-BY-NC-ND 4.0 International license.

900 activity. Standards are shown in A and B for ease of comparison to products. Formula weight for

901 DCA is 392.57 atomic mass units (amu), 12-oxoLCA is $390.56 \mathrm{amu}$, epiDCA is $392.57 \mathrm{amu}$. 
A.

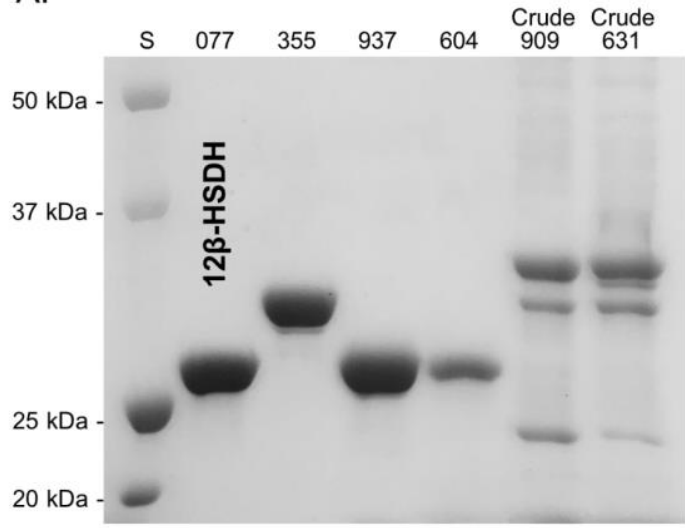

B.

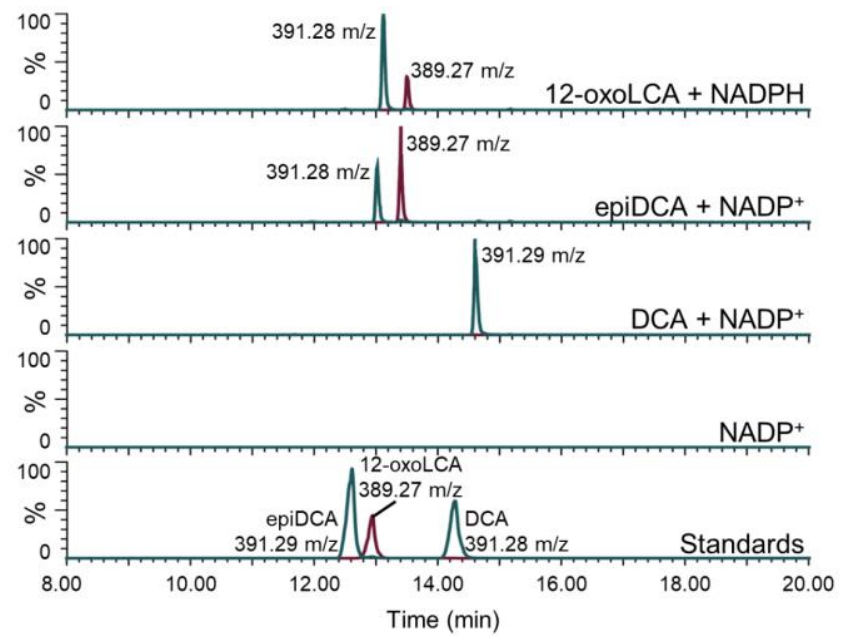

903 Figure 3. Identification of a gene encoding 12ß-HSDH. (A) SDS-PAGE of candidate

904 Clostridium paraputrificum $12 \beta-\mathrm{HSDH}$ proteins that were heterologously expressed in E. coli and

905 purified with TALON® metal affinity resin. Lanes are as follows: S, molecular weight protein

906 standard; 077, WP_027099077.1； 355，WP_027098355.1；937，WP_027097937.1； 604,

907 WP_027098604.1; 909, WP_027096909.1; 631, WP_027099631.1. (B) Representative negative

908 ion mode LC-MS chromatograms in single ion monitoring mode overlaid with linked vertical axes

909 of WP_027099077.1 reaction products compared to deoxycholic acid (DCA), 12-oxolithocholic

910 acid (12-oxoLCA) and epiDCA standards. Standards were run on a separate day and show a slight

911 offset in elution time. Reactions consisted of 10 nM WP_027099077.1 with $50 \mu \mathrm{M}$ (or no)

912 substrate, $150 \mu \mathrm{M}$ pyridine nucleotide in $50 \mathrm{mM}$ sodium phosphate, $150 \mathrm{mM}$ sodium chloride

913 buffer at $\mathrm{pH}$ 7.0. Formula weight for DCA is 392.57 atomic mass units (amu), 12-oxoLCA is

$914 \quad 390.56 \mathrm{amu}$, epiDCA is $392.57 \mathrm{amu}$.

915 
A.

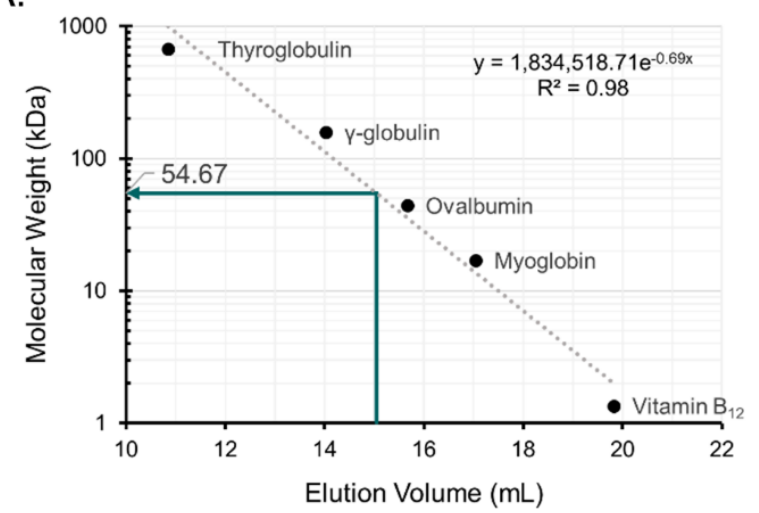

B.

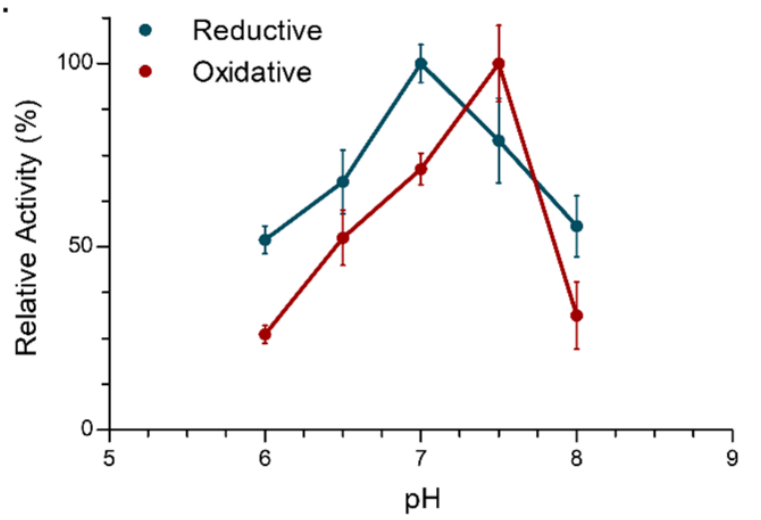

917 Figure 4. Biochemical characterization of recombinant $C$. paraputrificum 12ß-HSDH. (A)

918 Native molecular size analysis of $10 \mathrm{mg} / \mathrm{mL}$ purified $12 \beta-\mathrm{HSDH}$ via size-exclusion

919 chromatography. (B) Effect of $\mathrm{pH}$ on $12 \beta-\mathrm{HSDH}$ activity. The reaction in the reductive direction

920 (blue) consisted of 12-oxoLCA as substrate with NADPH as cofactor. The oxidative reaction (red)

921 was epiDCA with $\mathrm{NADP}^{+}$. See Materials and Methods for buffer compositions. 


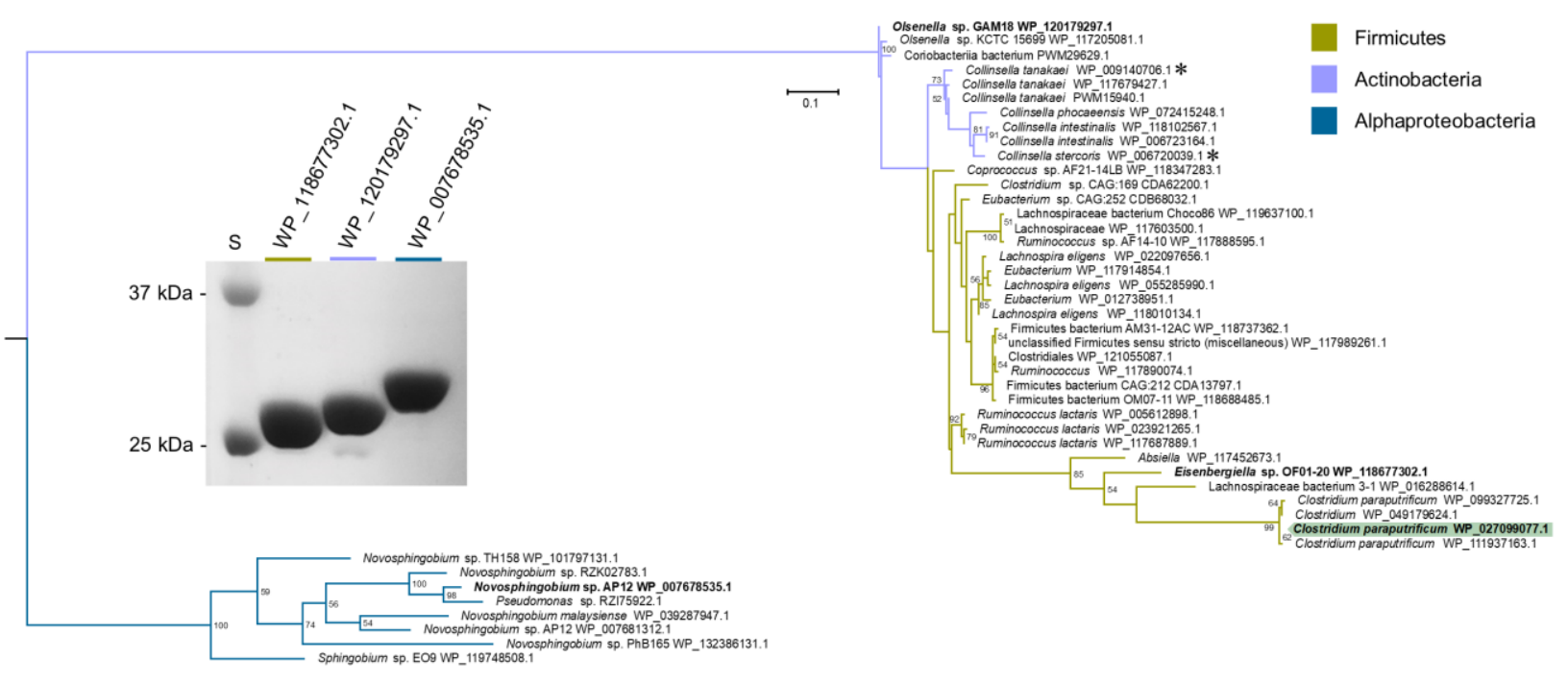

924 Figure 5. Maximum-likelihood tree based on a subset of the taxa present in the full 925 phylogenetic analysis of 12ß-HSDH and SDS-PAGE of proteins explored further. Sequences

926 selected for this analysis were those nearest to the C. paraputrificum 12 $\beta$-HSDH (highlighted),

927 plus an outgroup. For the full tree with about 5,000 sequences, see Figure S1. Taxonomic 928 affiliations are indicated by branch colors as specified in the legend. Bolded sequences were

929 chosen for further study. Asterisks indicate novel C-12 epimerizing organisms. (Inset) SDS-PAGE

930 of purified recombinant Eisenbergiella WP_118677302.1, Olsenella WP_120179297.1, and

931 Novosphingobium WP_007678535.1 heterologously expressed in E. coli and purified with

932 TALON® metal affinity resin. S, molecular weight protein standard. 
A.

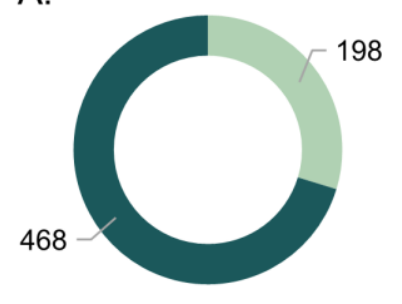

" Subjects with gene present

- Subjects without gene present

B.

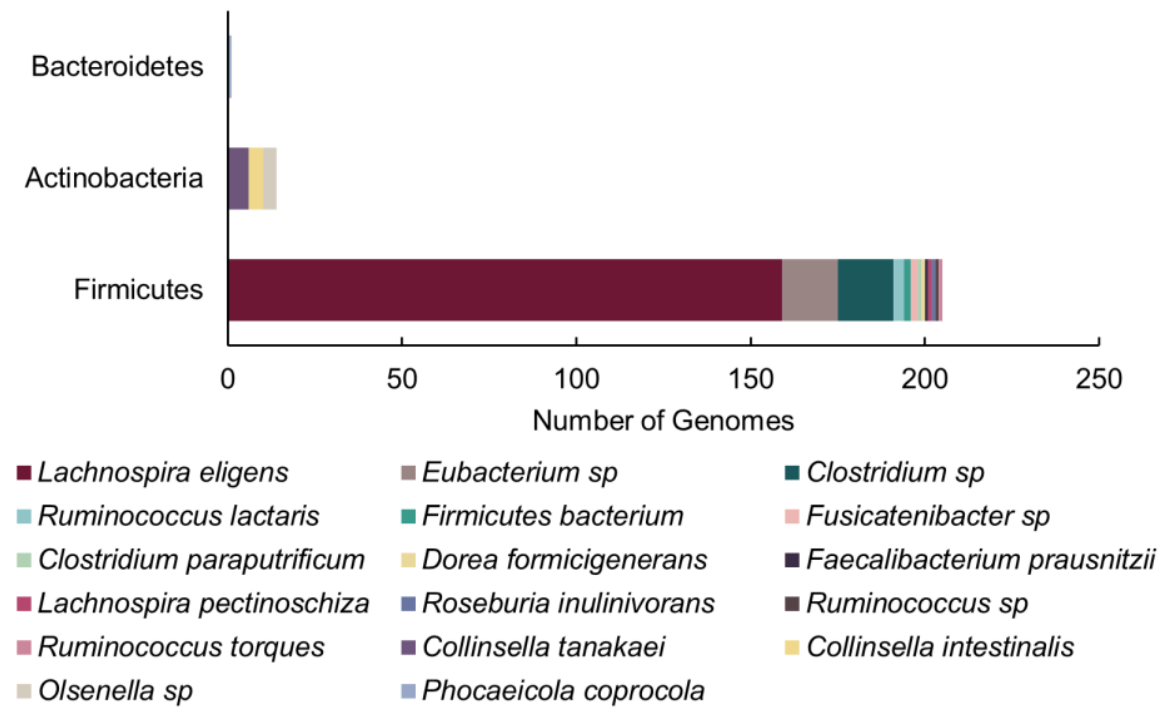

936 putative $12 \beta-H S D H$ genes present in their gut metagenomes. The metagenomes analyzed were

937 from 4 distinct cohorts. (B) Distribution of microbial genomes with putative 12 $\beta$-HSDH genes

938 present across the 4 metagenomic studies. 


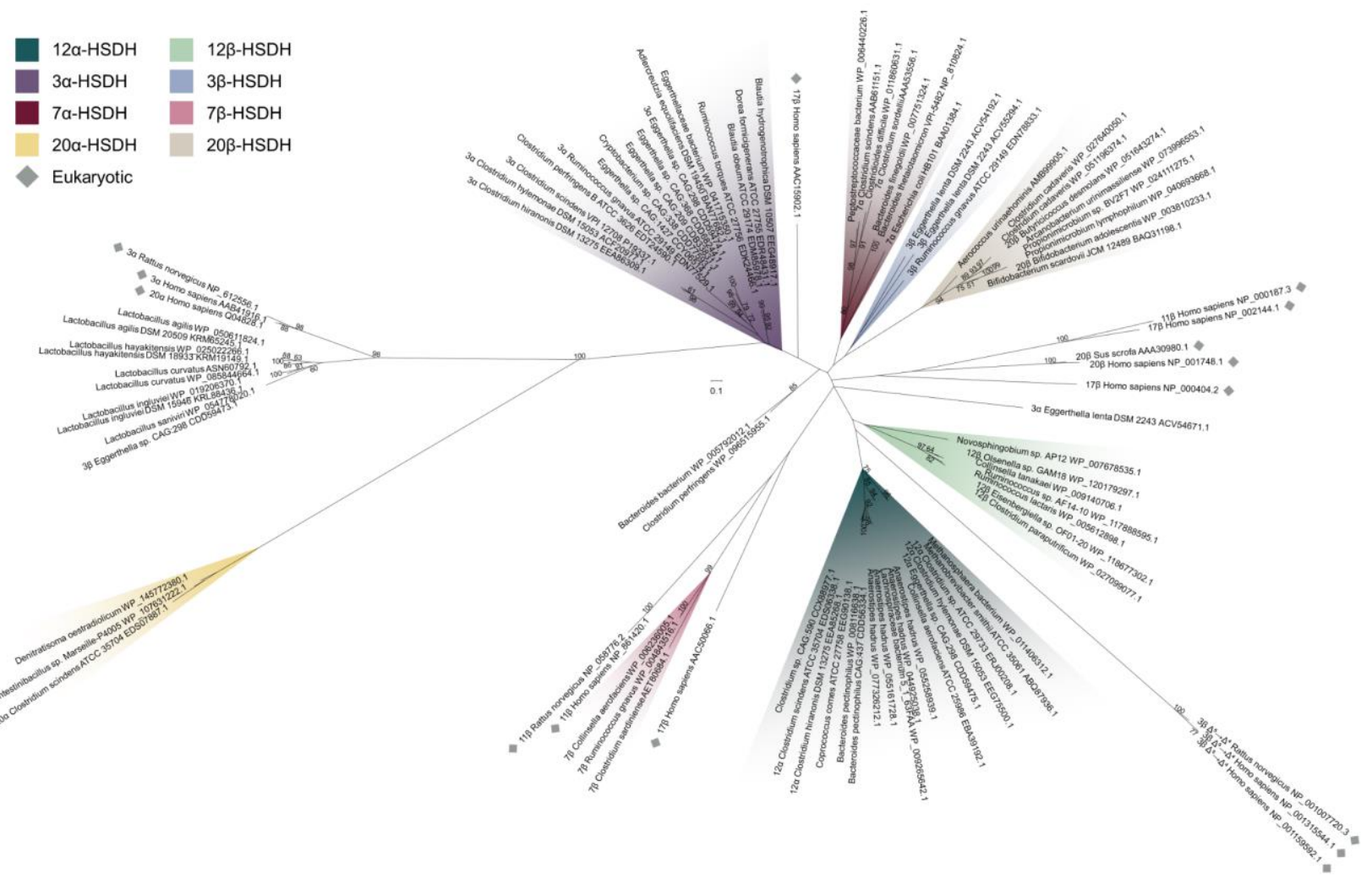

941 Figure 7. Maximum-likelihood phylogenetic analysis of regio- and stereospecific HSDHs.

942 Clusters are shaded by function or marked as eukaryotic, as displayed in the legend. Sequences

943 with experimentally determined activities are labeled with their function followed by organism

944 and accession number. See Table S2 for sequence information. 
bioRxiv preprint doi: https://doi.org/10.1101/2020.09.27.315549; this version posted February 26,2021 . The copyright holder for this preprint (which was not certified by peer review) is the author/funder, who has granted bioRxiv a license to display the preprint in perpetuity. It is made available under aCC-BY-NC-ND 4.0 International license.

\section{Tables}

949 Table 1. Steady-state kinetic parameters of purified recombinant $12 \beta-H S D H$.

\begin{tabular}{|c|c|c|c|c|c|}
\hline \multirow[b]{2}{*}{ Enzyme } & \multirow[b]{2}{*}{ Kinetic parameter } & \multicolumn{4}{|c|}{ Substrate or cofactor ${ }^{a}$} \\
\hline & & 12-oxoLCA ${ }^{b}$ & NADPH & epiDCA & NADP $^{+}$ \\
\hline \multirow[t]{4}{*}{ Cp12ß-HSDH } & $K_{m}(\mu \mathrm{M})$ & $18.76 \pm 0.40^{c}$ & $29.16 \pm 0.42$ & $44.43 \pm 1.13$ & $36.84 \pm 0.55$ \\
\hline & $k_{\text {cat }}\left(\mathrm{s}^{-1}\right)$ & $26.62 \pm 1.62$ & $28.15 \pm 1.74$ & $59.32 \pm 5.47$ & $44.61 \pm 3.77$ \\
\hline & $V_{\max }\left(\mu \mathrm{mol} \cdot \mathrm{min}^{-1} \cdot \mathrm{mg}^{-1}\right)$ & $58.41 \pm 3.56$ & $61.75 \pm 3.82$ & $130.13 \pm 12.01$ & $97.87 \pm 8.27$ \\
\hline & $k_{\text {cat }} / K_{m}\left(\mu \mathrm{M}^{-1} \cdot \mathrm{s}^{-1}\right)$ & $1.42 \pm 0.11$ & $0.97 \pm 0.07$ & $1.34 \pm 0.15$ & $1.21 \pm 0.12$ \\
\hline
\end{tabular}

$950{ }^{a}$ Assays were performed at saturating concentrations of components not being tested (refer to Materials and Methods).

$951 \quad{ }^{b}$ 12-oxolithocholic acid (12-oxoLCA), epideoxycholic acid (epiDCA).

$952{ }^{c}$ Values represent the mean $\pm \mathrm{SD}$ of three or more replicates.

953

954 Table 2. Substrate and pyridine nucleotide specificity of purified recombinant $C$. paraputrificum 955 12ß-HSDH, Eisenbergiella WP_118677302.1, Olsenella WP_120179297.1, and

956 Novosphingobium WP_007678535.1.

\begin{tabular}{|c|c|c|c|c|}
\hline Enzyme & Substrate $a, b$ & Cofactor & $\begin{array}{c}\text { Activity } \\
\left(\mu \mathrm{mol} \cdot \mathrm{min}^{-1} \cdot \mathrm{mg}^{-1}\right)\end{array}$ & Relative activity (\%) \\
\hline \multirow{4}{*}{ Cp12ß-HSDH } & 12-oxoLCA & NADPH & $18.26 \pm 1.01^{c}$ & 100 \\
\hline & 12-oxoLCA & $\mathrm{NADH}$ & $-\bar{d}$ & - \\
\hline & 12-oxoCDCA & NADPH & $2.21 \pm 0.82$ & 12.08 \\
\hline & 3,12-dioxoLCA & NADPH & $3.49 \pm 0.34$ & 19.09 \\
\hline WP_118677302.1 & 12-oxoLCA & NADPH & $16.04 \pm 1.23$ & 87.85 \\
\hline WP_120179297.1 & 12-oxoLCA & NADPH & $23.29 \pm 2.57$ & 127.57 \\
\hline WP_007678535.1 & 12-oxoLCA & NADPH & - & - \\
\hline \multirow{6}{*}{ Cp12ß-HSDH } & epiDCA & $\mathrm{NADP}^{+}$ & $33.42 \pm 0.81$ & 100 \\
\hline & epiDCA & $\mathrm{NAD}^{+}$ & - & - \\
\hline & epiCA & $\mathrm{NADP}^{+}$ & $8.99 \pm 0.90$ & 26.88 \\
\hline & DCA & $\mathrm{NADP}^{+}$ & - & - \\
\hline & $\mathrm{CA}$ & $\mathrm{NADP}^{+}$ & - & - \\
\hline & CDCA & $\mathrm{NADP}^{+}$ & - & - \\
\hline WP_118677302.1 & epiDCA & $\mathrm{NADP}^{+}$ & $27.85 \pm 1.12$ & 83.32 \\
\hline WP_120179297.1 & epiDCA & $\mathrm{NADP}^{+}$ & $23.02 \pm 2.57$ & 68.86 \\
\hline WP_007678535.1 & epiDCA & NADP $^{+}$ & - & - \\
\hline
\end{tabular}

$958{ }^{b}$ Assays were performed with $10 \mathrm{nM}$ enzyme, $50 \mathrm{uM}$ substrate and $150 \mathrm{uM}$ cofactor at optimum $\mathrm{pH}$.

$959{ }^{c}$ Values represent the mean \pm SD of three or more replicates.

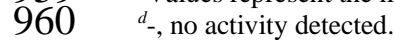

